DNA Library of Life, research article

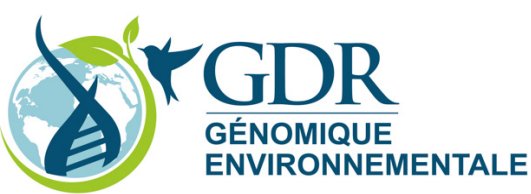

urn:1sid:zoobank.org:pub:8B9DADD0-415E-4120-A10E-8A3411C1C1A4

\title{
Biodiversity and phylogeny of Ammotheidae (Arthropoda: Pycnogonida)
}

\author{
Romain SABROUX ${ }^{1}$, Laure CORBARI ${ }^{2}$, Franz KRAPP ${ }^{3}$, Céline BONILLO ${ }^{4}$, \\ Stépahnie LE PRIEUR ${ }^{5} \&$ Alexandre HASSANIN ${ }^{6, *}$ \\ ${ }^{1,2,6}$ UMR 7205, Institut de Systématique, Evolution et Biodiversité, \\ Département Systématique et Evolution, Sorbonne Universités, Muséum national \\ d'Histoire naturelle, 55 rue Buffon, CP 51, 75005 Paris, France. \\ ${ }^{3}$ Zoologisches Forschungsmuseum Alexander Koenig, Adenauerallee 160, 53113 Bonn, Germany. \\ ${ }^{4,5}$ UMS CNRS 2700, Muséum national d'Histoire naturelle, CP 26, \\ 57 rue Cuvier, 75231 Paris Cedex 05, France. \\ ${ }^{*}$ Corresponding author: hassanin@mnhn.fr \\ ${ }^{1}$ Email: romain.sabroux@mnhn.fr \\ ${ }^{2}$ Email: corbari@mnhn.fr \\ ${ }^{3}$ Email: franz.krapp.zfmk@uni-bonn.de \\ ${ }^{4}$ Email: bonillo@mnhn.fr \\ ${ }^{5}$ Email: sleprieur@mnhn.fr

\footnotetext{
${ }^{1}$ urn:1sid:zoobank.org:author:F48B4ABE-06BD-41B1-B856-A12BE97F9653

${ }^{2}$ urn:lsid:zoobank.org:author:9E5EBA7B-C2F2-4F30-9FD5-1A0E49924F13

${ }^{3}$ urn:1sid:zoobank.org:author:331AD231-A810-42F9-AF8A-DDC319AA351A

${ }^{4}$ urn:lsid:zoobank.org:author:7333D242-0714-41D7-B2DB-6804F8064B13

${ }^{5}$ urn:lsid:zoobank.org:author:5C9F4E71-9D73-459F-BABA-7495853B1981

${ }^{6}$ urn:1sid:zoobank.org:author:0DCC3E08-B2BA-4A2C-ADA5-1A256F24DAA1
}

\begin{abstract}
The family Ammotheidae is the most diversified group of the class Pycnogonida, with 297 species described in 20 genera. Its monophyly and intergeneric relationships have been highly debated in previous studies. Here, we investigated the phylogeny of Ammotheidae using specimens from poorly studied areas. We sequenced the mitochondrial gene encoding the first subunit of cytochrome c oxidase (CO1) from 104 specimens. The complete nuclear 18S rRNA gene was sequenced from a selection of 80 taxa to provide further phylogenetic signal. The base composition in $\mathrm{CO} 1$ shows a higher heterogeneity in Ammotheidae than in other families, which may explain their apparent polyphyly in the $\mathrm{CO} 1$ tree. Although deeper nodes of the tree receive no statistical support, Ammotheidae was found to be monophyletic and divided into two clades, here defined as distinct subfamilies: Achelinae comprises the genera Achelia Hodge, 1864, Ammothella Verrill, 1900, Nymphopsis Haswell, 1884 and Tanystylum Miers, 1879; and Ammotheinae includes the genera Ammothea Leach, 1814, Acheliana Arnaud, 1971, Cilunculus Loman, 1908, Sericosura Fry \& Hedgpeth, 1969 and also Teratonotum gen. nov., including so far only the type species Ammothella stauromata Child, 1982. The species Cilunculus gracilis Nakamura \& Child, 1991 is reassigned to Ammothella, forming the binomen Ammothella gracilis (Nakamura \& Child, 1991) comb. nov. Additional taxonomic re-arrangements are suggested for the genera Achelia, Acheliana, Ammothella and Cilunculus.
\end{abstract}


Keywords. Pantopoda, taxonomy, DNA phylogeny, barcode of life, strand-bias.

Sabroux R., Corbari L., Krapp F., Bonillo C., Le Prieur S. \& Hassanin A. 2017. Biodiversity and phylogeny of Ammotheidae (Arthropoda: Pycnogonida). European Journal of Taxonomy 286: 1-33. http://dx.doi.org/10.5852/ ejt.2017.286

\section{Introduction}

Sea spiders (Arthropoda: Pycnogonida: Pantopoda) represent a small group of exclusively marine arthropods which are distributed worldwide, from the tropical to the polar regions, from littoral to abyssal depths. There are 1385 described species that are classified in 79 genera and 11 families (Bamber et al. 2015). They exhibit a typical "spider-like" appearance, with generally four pairs of walking legs attached to a slender trunk. They show a remarkable diversity of forms (from the slender Nymphon Fabricius, 1794 to the stout Pycnogonum Brünnich, 1764), a variable number of leg pairs (from 4 to 6), a wide size range (leg span from 1 to $700 \mathrm{~mm}$ ) and a great diversity of colours, ranging from the palest to the most colourful (e.g., the multi-coloured Anoplodactylus evansi Clark, 1963) (Arnaud \& Bamber 1987; Bamber et al. 2015). The position of sea spiders as a class of the subphylum Chelicerata is accepted by most recent molecular studies (Regier et al. 2010; Rehm et al. 2014; Roeding et al. 2009).

The pycnogonid families were distinguished based on the presence/absence and the structure of the three cephalic appendages: chelifores, palps and ovigers (e.g., Hedgpeth 1948). However, the number of families has varied heavily during the taxonomic history of Pycnogonida, from 8 families in Hedgpeth (1948) to 27 in Fry (1978). More recent classifications have recognized between 9 (Arnaud \& Bamber 1987) and 11 families (Bamber 2007b). The position of some genera was also highly debated (e.g., Pallenopsis Wilson, 1881, Endeis Philippi, 1843, Tanystylum Miers, 1879). The four previous molecular studies on pycnogonids have questioned the validity of several families (Arango 2003b; Arango \& Wheeler 2007; Nakamura et al. 2007; Arabi et al. 2010). Among them, the most problematic taxon probably remains the family Ammotheidae.

Originally, Dohrn (1881) gave an extensive definition of Ammotheidae by integrating the genera Ammothea Leach, 1814, Barana Dohrn, 1881 (currently accepted as Ascorhynchus Sars, 1878), Clotenia Dohrn, 1881 (accepted as Tanystylum) and Trygaeus Dohrn, 1881. Later during the same year, Hoek (1881) created the family Ascorhynchidae combining Ascorhynchus, Ammothea and Tanystylum, inter alia. The question of splitting Ammothea and Ascorhynchus (and their respective relatives) into two families has always been a matter of debate, because they show puzzling combinations of characters (e.g., the same chelae reduction vs different oviger structures). While most specialists included them in a single family (e.g., Arnaud \& Bamber 1987; Dohrn 1881; Hedgpeth 1941; Hoek 1881; Nakamura \& Child 1991; Stephensen 1933; Stock 1994), some early authors split them into two families (e.g., Bouvier 1923). Finally, molecular studies (Arango \& Wheeler 2007; Nakamura et al. 2007; Arabi et al. 2010) cast doubt on the hypothesis of a single family (which was Ammotheidae according the priority rule of taxonomic nomenclature). Nakamura et al. (2007) suggested the resurrection of the family Ascorhynchidae, a position that was followed by the commonly used classifications of Bamber (2007b; 2015), but Ascorhynchidae and Ammotheidae were grouped into the same superfamily Ascorhynchoidea Hoek, 1881 (and not "Pocock, 1904" as listed by Bamber 2007b and Bamber et al. 2015).

Even now, the status of Ammotheidae sensu Bouvier (1923) (i.e., excluding Ascorhynchidae) is rather unclear. As previously commented by Bouvier, most of the characters used to describe this reduced taxon show exceptions: for instance, their main character, i.e., the reduction of chelae to small buds, is not constant (for example, adults of Nymphopsis muscosa Loman, 1908 bear chelate chelae); the number of palp articles is highly variable (4 to 9); the abdomen can be articulated or not to the trunk, and their development can be direct or larval (Bamber 2007b). The family Ammotheidae sensu Bouvier (1923) 
was found to be poly- or paraphyletic in the molecular studies of Nakamura et al. (2007) and Arango \& Wheeler (2007). However, these results may have been caused by the use of unreliable molecular data (carryover DNA contamination and high levels of missing data, inaccurate methods of DNA alignment and the extreme heterogeneity of nucleotide composition in the mitochondrial genes of sea spiders, see Arabi et al. 2010). Nevertheless, the taxon was recovered monophyletic in the tree obtained from a concatenation of five mitochondrial and nuclear markers, but based on only ten species (of the 297 described) (Arabi et al. 2010). Therefore, we consider that the status of Ammotheidae is an open question that needs to be studied with a better taxonomic sampling, including more species diversity.

Previous studies on sea spiders have mainly focused on species from the Southern Ocean. As a consequence, we have a great amount of knowledge on this fauna in terms of biodiversity (León 2001; Munilla \& Soler-Membrives 2009, 2015), integrative taxonomy, population genetics (Arango et al. 2011; Dietz et al. 2015; Krabbe et al. 2010), biogeography (Griffiths et al. 2011; Munilla \& SolerMembrives 2009) and parasitology (Schiaparelli et al. 2008). Historically, one of the first invertebrate species described from Antarctica was a sea spider (Decolopoda australis Eights, 1835) and since then, pycnogonids have been considered as a flagship group in Antarctica. Moreover, taxonomists were particularly interested in Antarctic sea spiders because of their large size and their "extra-legged" representatives (ten legs or more) (e.g., Bouvier 1910). In contrast, species from non-Antarctic regions are often tiny in size, and thus more difficult to collect or study by non-specialists. As a consequence, most of the barcode sequences ( 5 ' fragment of the gene encoding the first subunit of cytochrome $\mathrm{c}$ oxidase, CO1) currently available for Ammotheidae in the nucleotide databases come from southern ecoregions (South Australia, South America and Antarctica; Fig. 1).

Here, we investigated the diversity and phylogeny of Ammotheidae by focusing on sea spiders collected in several poorly studied tropical areas (e.g., Papua New Guinea, South Madagascar, Marquesas Islands) during the latest expeditions of the Muséum national d'Histoire naturelle of Paris (MNHN). We generated 104 sequences of the CO1 mitochondrial gene and 80 sequences of the 18S rRNA (18S) nuclear gene. These datasets were analysed to address the following three main questions: (1) Are Ammotheidae monophyletic? (2) Are the "big five" ammotheid genera (Ammothea, Achelia Hodge, 1864, Ammothella Verrill, 1900, Cilunculus Loman, 1908 and Tanystylum) monophyletic? (3) How heterogeneous is the base composition in $\mathrm{CO} 1$ sequences of Ammotheidae?

\section{Material and methods}

\section{Sampling}

The specimens selected for this study were collected during the following MNHN expeditions and deep sea cruises (Fig. 2), organized under the "Planète Revisitée" and "Tropical Deep Sea Benthos" programs (Bouchet et al. 2008; Richer de Forges et al. 2013): BATHUS 3 (New Caledonia, 1993), SANTO (Vanuatu, 2006), CEAMARC (Antarctica, 2008), MAINBAZA (Mozambique Channel, 2009), ATIMO VATAE (South Madagascar, 2010), BIOPAPUA (Bismarck Sea, Papua New Guinea, 2010), PAPUA NIUGINI (Madang, Papua New Guinea, 2012), PAKAIHI I TE MOANA (Marquesas Islands, 2012), KARUBENTHOS (Guadeloupe, 2012); KAVIENG (Kavieng, Papua New Guinea, 2014), GUYANE 2014 (off French Guiana, 2014), and ILES DU SALUT (French Guiana, 2014). Details of the field operations are available at http://expeditions.mnhn.fr/. Some additional specimens have been provided by IFREMER (BICOSE, BIOBAZ, HYDROMAR and FUTUNA 3 cruises). All the geographical locations are reported in Appendix 1. The specimens were collected from littoral shores to hydrothermal vents (3500 m depth).

\section{DNA extraction, amplification and sequencing}

Total DNA was extracted from a leg removed on specimens preserved in $80-95 \%$ ethanol using the QIAamp DNA Micro Kit (Qiagen, Hilden, Germany). The samples were lysed in $360 \mu 1$ of ATL (twice 
as much as recommended by the manufacturer) and $40 \mu 1$ of proteinase $\mathrm{K}$. The volumes of AL and ethanol were also doubled. The rest of the protocol followed the volumes indicated by the manufacturer. Final extract volumes contained between 25 and $100 \mu 1$ of DNA solution.

Two markers were sequenced for this study: the mitochondrial CO1 gene and the nuclear $18 \mathrm{~S}$ gene. We used a new set of primers to amplify CO1 sequences (Py-CO1-U: 5'-TCA-ACW-AAT-CAT-AAA-GAYATT-GG-3' and Py-CO1-L3: 5'-GGR-TCH-CCH-CCH-GMD-GGR-TC-3') and the three sets used in previous studies for the $18 \mathrm{~S}$ sequences (see details in Arabi et al. 2010). DNA amplification were done using Hot start mix RTG Taq (GE Healthcare, Waukesha, WI, USA) in a $25 \mu 1$ final volume containing between 1 and $5 \mu 1$ of DNA and $1 \mu 1$ of each $10 \mathrm{mM}$ primer. Initial denaturation was performed at $94^{\circ} \mathrm{C}$ for $4 \mathrm{~min}$, then we applied 40 cycles of denaturation-hybridization of $30 \mathrm{~s}$ at $94^{\circ} \mathrm{C}, 30 \mathrm{~s}$ at hybridization temperature $\left(50^{\circ} \mathrm{C}\right.$ for $\mathrm{CO} 1,52^{\circ} \mathrm{C}$ for $\left.18 \mathrm{~S}\right)$, and $1 \mathrm{~min}$ at $72^{\circ} \mathrm{C}$. Final elongation lasts $10 \mathrm{~min}$ at $72^{\circ} \mathrm{C}$. Purification and cycle sequencing were performed by Eurofins (Munich, Germany) using the PCR primers detailed above.

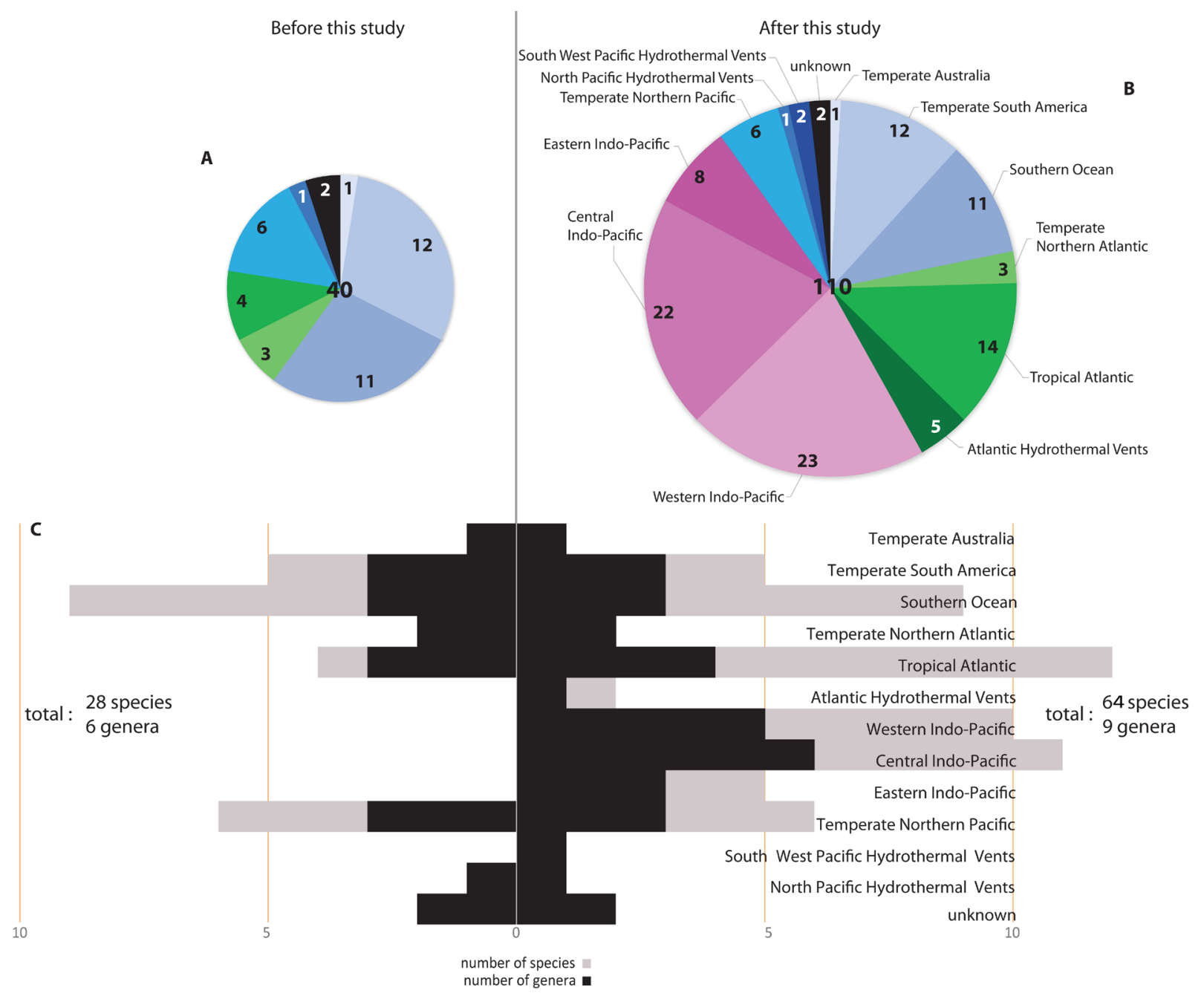

Fig. 1. Barcode richness in GenBank before and after this study. A-B. Number of CO1 haplotypes before (A) and after (B) this study as a function of the origins of the specimens sequenced. $\mathbf{C}$. Number of species (grey) and genera (black) represented by a $\mathrm{CO} 1$ sequence found in GenBank databases before (left) and after (right) this study, classified by ecoregions. Littoral ecoregions defined according to Spalding et al. (2007) and abyssal ecoregions following a simplification of Bachraty et al. (2009). 
The sequences were cleaned using CodonCode Aligner v. 3.7.1 (CodonCode Corporation, Dedham, MA, USA) by comparing forward and reverse electrophoregrams. Nucleotide ambiguities were coded according to the IUPAC nomenclature. Cleaning was achieved after multiple DNA alignments using Se-Al v. 2.0a11 (Rambaut 2002). Each sequence was compared via BLAST methods (NCBI, Benson et al. 2015 ) in order to detect potential contaminations. The sequences were deposited in GenBank under accession numbers KX535346-KX535450 (CO1) and KX536422-KX536501 (18S).

\section{Phylogenetic analyses}

The $104 \mathrm{CO} 1$ barcodes and 80 18S sequences generated for this study were compared to all sequences of Ammotheidae (48) and Aschorhynchidae (19) downloaded from GenBank. For other pycnogonid families, we selected only species for which both $\mathrm{CO} 1$ and $18 \mathrm{~S}$ sequences were available. Details on the $75 \mathrm{CO} 1$ and 79 18S sequences from GenBank are provided in Appendix 1. The pycnogonid tree was rooted with 10 outgroup species, including two chelicerates (Uropygi: Mastigoproctus giganteus (Lucas, 1835); Xiphosura: Limulus polyphemus (Linnaeus, 1785)), six mandibulates (Stomatopoda: Squilla empusa Say, 1818; Branchiopoda: Triops longicaudatus LeConte, 1846; Chilopoda: Lithobius variegatus Leach, 1814 and L. forficatus (Linnaeus, 1785); Diplopoda: Thyropygus sp. and Orthoporus sp.) and two onychophorans (Opisthopatus cinctipes Purcell, 1899 and Peripatoides novaezaelandiae (Hutton, 1876)). We avoided CO1 sequences characterized by an inverted bias in base composition (e.g., scorpions, spiders, etc.) in order to limit artefacts during phylogenetic reconstruction. This strategy was determined in agreement with previous studies showing that asymmetric mutational constraints occurred during the evolution of the mitochondrial genome of Chelicerata, including sea spiders (Hassanin et al. 2005; Hassanin 2006; Arabi et al. 2010, 2012).

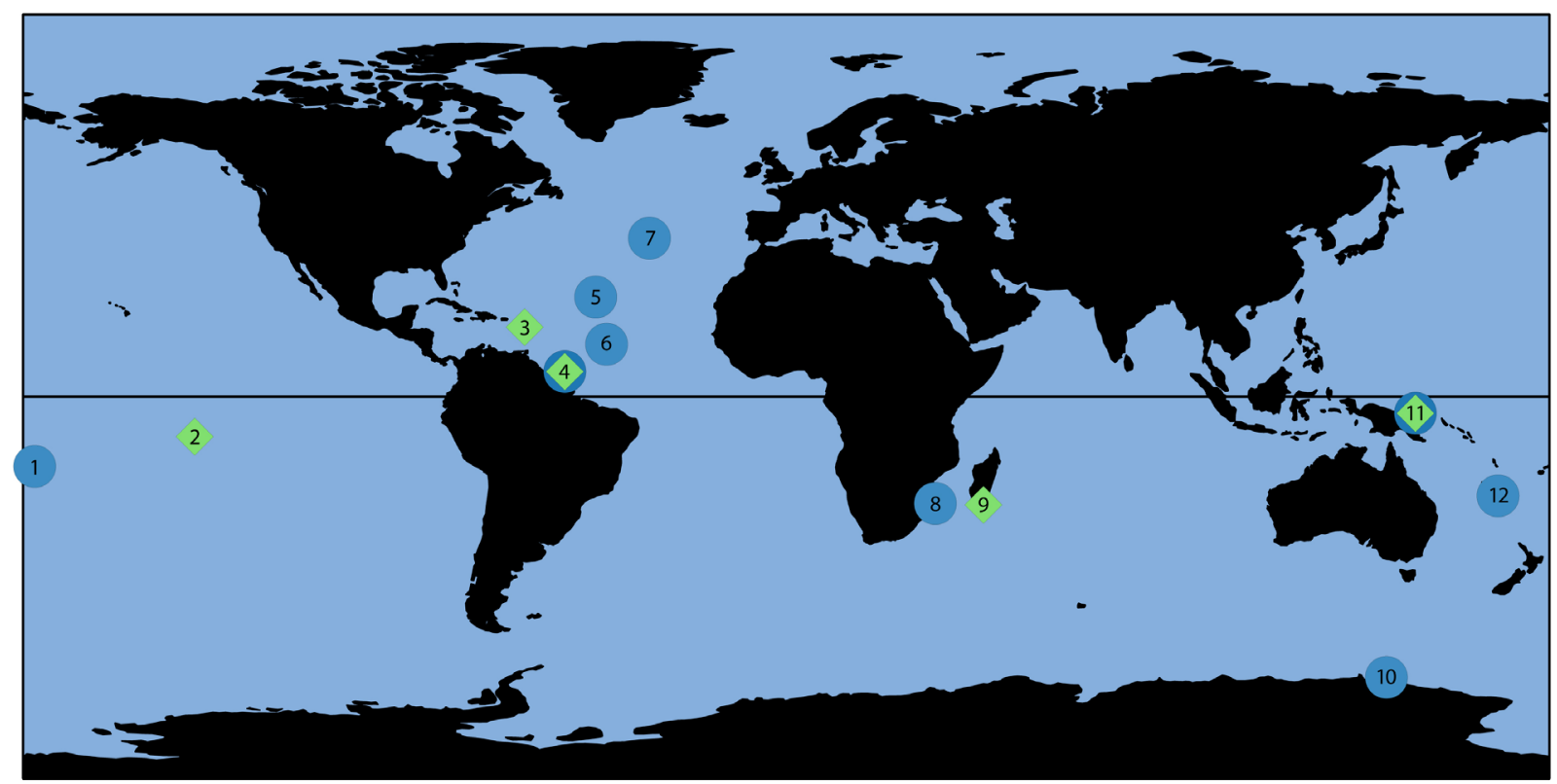

Fig. 2. Regional distribution of the studied specimens. Green diamonds indicate locations where specimens were collected at shallow depths $(<100 \mathrm{~m})$, blue circles those from deep-sea samplings; the combinations of both symbols indicates mixed samplings (below and above $100 \mathrm{~m}$ depth). 1: Futuna; 2: Marquesas Islands; 3: Guadeloupe; 4: French Guiana; 5: Mid-Atlantic Ridge, Snake Pit site; 6: MidAtlantic Ridge, Logatchev site; 7: Mid-Atlantic Ridge, Lucky Strike site; 8: Mozambique Channel; 9: South Madagascar; 10: Antarctica, Terre Adélie; 11: Papua New Guinea; 12: New Caledonia and Vanuatu. 
The $18 \mathrm{~S}$ alignment was achieved using a first trial with CodonCode Aligner v. 3.7.1, and it was optimized manually on Se-Al v. 2.0a11. Several regions with too many ambiguous positions for homology were removed from the analyses. In other regions that are difficult to align, but which provide phylogenetic information at lower taxonomic levels, we chose a different strategy based on the use of different taxonomic blocks. For instance, the region located at positions 679-693 (with respect to the DQ389932 sequence) was aligned using four shifted blocks corresponding to the following taxa: (1) Ammotheidae Dohrn, 1881, Nymphonidae Wilson, 1878, Callipallenidae Hilton, 1942 and Pallenopsidae Fry, 1978, (2) Ascorhynchidae Hoek, 1881 and Endeidae Norman, 1908, (3) Phoxichilidiidae Sars, 1891, and (4) Colossendeidae Jarvinsky, 1870, Pycnogonidae Wilson, 1878 and Austrodecidae Stock, 1954.

Phylogenetic analyses were performed with MrBayes v. 3.2.2 (Ronquist \& Huelsenbeck 2003), running 4 chains for 10 million generations, and a 25\% burn-in. We analysed the $18 \mathrm{~S}$ and CO1 (partitioned by codon positions or without partition) datasets separately, and the model (i.e., GTR $+\mathrm{G}+\mathrm{I}$ ) was selected using the best AIC score calculated on jModelTest (Posada 2008). For the reduced dataset of 135 taxa used for the concatenation of $\mathrm{CO} 1$ and $18 \mathrm{~S}$ markers, we performed a partitioned analysis using a GTR for each marker.

\section{Analysis of the nucleotide compostion in COI sequences}

Strand-bias in nucleotide composition was analysed at third codon positions of CO1 sequences. As similar trends were previously found for two- and fourfold degenerate sites (Hassanin et al. 2005), we followed the simplified approach previously published in Arabi et al. (2010), in which AT and CG skews were calculated on all third codon positions of $\mathrm{CO} 1$ sequences using the following formulas: AT skew $=\left(\mathrm{F}_{\mathrm{A}}-\mathrm{F}_{\mathrm{T}}\right) /\left(\mathrm{F}_{\mathrm{A}}+\mathrm{F}_{\mathrm{T}}\right)$ and $\mathrm{CG}$ skew $=\left(\mathrm{F}_{\mathrm{C}}-\mathrm{F}_{\mathrm{G}}\right) /\left(\mathrm{F}_{\mathrm{C}}+\mathrm{F}_{\mathrm{G}}\right)$, where $\mathrm{F}$ is the frequency of the considered nucleotide at third codon positions. The skew values were considered as significant if the null hypothesis could be rejected to a confidence level of $5 \%$.

\section{Results}

\section{Datasets}

The great extent of localities and depth range explored here allowed us to examine a large diversity of pycnogonids from 8 of the 11 families and from the seven main genera of Ammotheidae, except Ammothea (i.e., Achelia, Ammothella, Cilunculus, Nymphopsis Haswell, 1884, Sericosura Fry \& Hedgpeth, 1969 and Tanystylum). The presently monospecific Acheliana Arnaud, 1971 is also sequenced for the first time with an undescribed species (in prep.). With the sequences extracted from GenBank (see Appendix 1), we included one additional ammotheid genus (Ammothea) and two other families (Austrodecidae and Colossendeidae) in the analyses.

We detected several potential errors in the GenBank sequences, involving substitutions in highly conserved regions (e.g., Ammothea hilgendorfi DQ389936; Anoplodactylus batangensis DQ389918), as well as unexpected indels in the $18 \mathrm{~S}$ stems, which are very constrained regions (see below) (e.g., Ascorhynchus castelloides DQ389905; Callipallene novaezealandiae DQ389927; Anoplodactylus batangensis DQ389918). However, these potential errors were not so problematic for phylogenetic inferences, since most of them are autapomorphic. More worrying is the misleading effect of the $18 \mathrm{~S}$ sequence of Pentapycnon charcoti (DQ389924) on phylogenetic reconstruction. Indeed, our preliminary analyses revealed its chimeric origin as positions 1 to 923 correspond to an undetermined fungus. In this case, we excluded the fungal part of the sequence from the alignment. Similar problems have previously been described in Arabi et al. (2010) for other sea spiders. Other sequences susceptible to generate reconstruction artefacts, due to their poor quality (highly divergent sequences in conserved regions) or their shortness, were removed from the analyses (CO1: Achelia alaskensis DQ390093; 18S: Pallenopsis macronyx DQ389908). 
The CO1 alignment contains 179 sequences (of which 104 are new) and 618 nucleotides representing 376 informative characters (369 without outgroups). It is worth noting that all specimens of the genus Eurycyde Schiödte, 1857 share a synapomorphic deletion of two codons in the CO1 gene (positions 472-477 in the DQ390087 sequence of Achelia assimilis). There is no significant difference between the $\mathrm{CO} 1$ analyses made with or without partition (Fig. 3). The 18S alignment contains 159 sequences (of which 80 are new) and 1750 nucleotides (including gaps due to alignment) representing 321 informative characters (idem without outgroups). The $18 \mathrm{~S}$ tree is shown in Fig. 4. The concatenation of the two markers contains 135 sequences and 2550 nucleotides representing 746 informative characters (602 without outgroups). The tree obtained from the concatenation is illustrated in Fig. 5.

\section{Phylogenetic relationships}

The monophyly of Pycnogonida is supported by maximal values of posterior probability $(\mathrm{PP}=1)$ in all analyses. Most families are monophyletic with high support $(\mathrm{PP}>0.9)$ in most analyses: Colossendeidae, Endeidae, Pallenopsidae, Phoxichilidiidae and Pycnogonidae. In the CO1 tree (Fig. 3), however, Pallenopsidae is recovered as paraphyletic $(\mathrm{PP}=0.87)$ and the monophyly of Phoxichilidiidae is less robust $(\mathrm{PP}<0.5)$. The family Ascorhynchidae is found to be monophyletic in the concatenated analysis $(\mathrm{PP}=0.9)$ (Fig. 5) and the $18 \mathrm{~S}$ analysis based on 135 specimens $(\mathrm{PP}=0.72)$ (Appendix 2), whereas different, but unrobust relationships are shown in other analyses $(\mathrm{PP}<0.6)$. All members of the families Callipallenidae and Nymphonidae are systematically grouped, but these taxa are always found to be either poly- or paraphyletic.

Within pycnogonids, most basal relationships are poorly supported $(\mathrm{PP}<0.8)$, but the families Austrodecidae and Pycnogonidae are found to be the first divergent lineages in most topologies (Figs 3-5, Appendix 2). However, these results only show good support in the combined analysis, where Austrodecidae and Pycnogonidae are the first and second offshoots, respectively ( $\mathrm{PP}>0.85)$. The family Colossendeidae is the next taxon to diverge in both combined and $18 \mathrm{~S}$ analyses, but this has only weak support ( $\mathrm{PP}=0.57-0.77$ ) (Figs 4-5). In the CO1 analyses (Fig. 3, Appendix 2), Colossendeidae appear as the sister-group of Phoxichilidiidae ( $\mathrm{PP}=0.69$ and 0.93 ), and they are allied to the clade uniting Nymphonidae and Callipallenidae ( $\mathrm{PP}=0.82)$ in the $\mathrm{CO} 1$ analysis based on 179 haplotypes (Fig. 3).

The clade uniting Callipallenidae and Nymphonidae is grouped with Ascorhynchidae in the $18 \mathrm{~S}$ and combined analyses ( $\mathrm{PP}=0.72-0.93$ ) (Figs 4-5, Appendix 2). In the CO1 analysis based on 135 specimens (Appendix 2), however, the paraphyletic ascorhynchids are grouped with some ammotheids (i.e., excluding the "Achelia sawayai group", see below) and Pallenopsidae $(\mathrm{PP}=0.81)$.

The family Ammotheidae appears to be monophyletic in the $18 \mathrm{~S}$ and $\mathrm{CO} 1+18 \mathrm{~S}$ trees with good supports $(\mathrm{PP}=0.83-0.95)$ (Figs 4-5, Appendix 2). The CO1 analyses (Fig. 3, Appendix 2), however, support its polyphyly ( $\mathrm{PP}=0.81-0.9)$ due to the position of the "Achelia sawayai group" (Achelia sawayai Marcus, $1940+$ Achelia sp. 15 + specimen MNHN-IU-2013-18602), which is found to be monophyletic with maximum support in all analyses $(\mathrm{PP}=1)$ and divergent from other Ammotheidae $(\mathrm{PP}=0.79)$.

Two major subfamilies of Ammotheidae can be distinguished: (1) Achelinae Wilson, 1881, which includes Achelia, Nymphopsis, Tanystylum, all Ammothella except A. stauromata Child, 1982 and A. biunguiculata Dohrn, 1881, and Cilunculus gracilis Nakamura \& Child, 1991 (see 18S analysis in Fig. 4); and (2) Ammotheinae Dohrn, 1881 emend., which is composed of the genera Ammothea, Acheliana, Sericosura, all Cilunculus but C. gracilis, and the species Ammothella stauromata and A. biunguiculata (see $18 \mathrm{~S}$ analysis in Fig. 4). The subfamily Ammotheinae is supported in all analyses, in general with highest support values. The subfamily Achelinae is monophyletic in the $18 \mathrm{~S}$ and $\mathrm{CO} 1+18 \mathrm{~S}$ trees $(\mathrm{PP}=1)($ Figs 4-5, Appendix 2), but paraphyletic in the CO1 trees ( $\mathrm{PP}=0.94-0.98)$ (Fig. 3, Appendix 2) because the "Achelia sawayai group" appears as the sister-group of Endeidae 


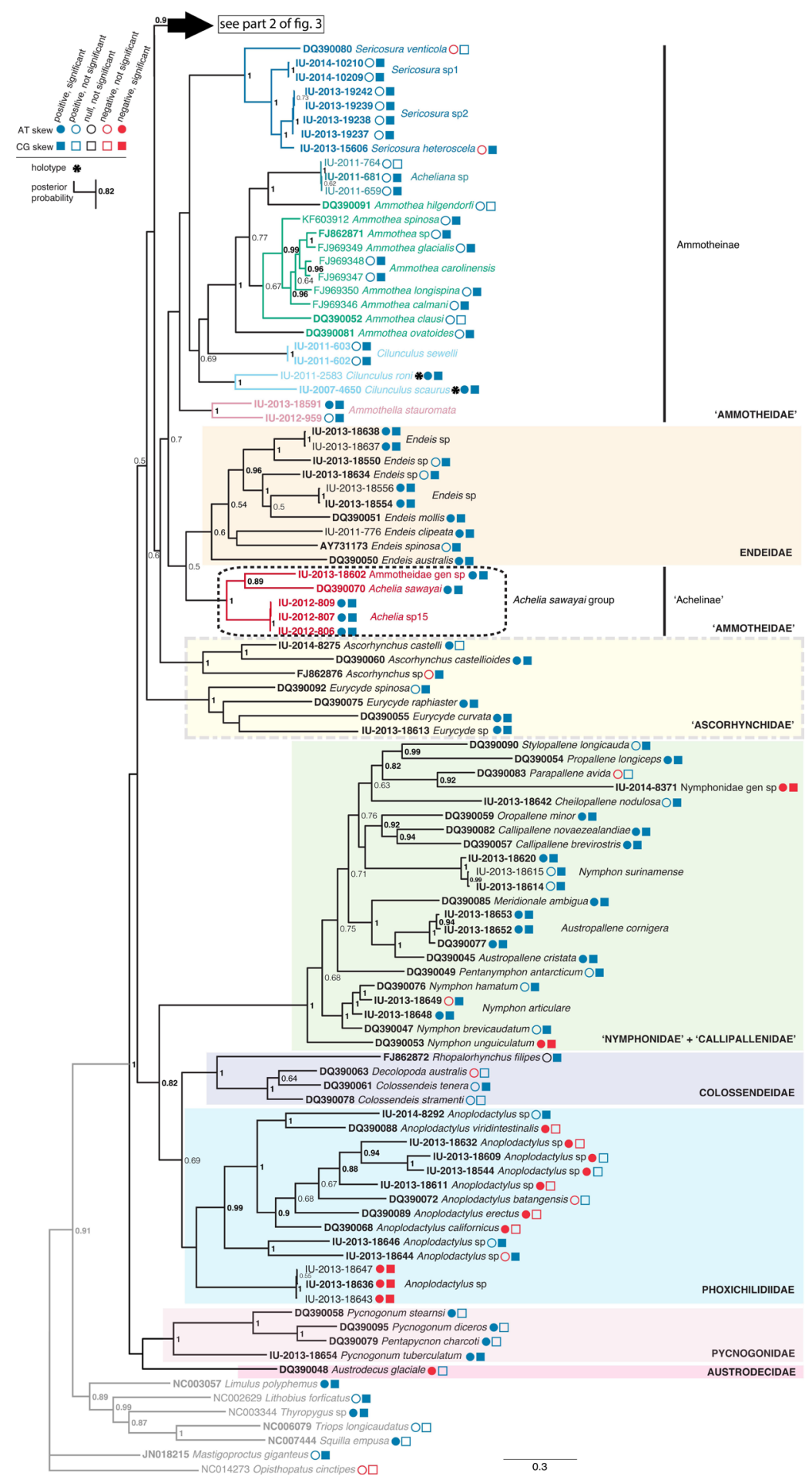

Fig. 3. Bayesian tree of Pycnogonida based on 179 sequences of the mitochondrial CO1 gene (partitioned analysis). Coloured rectangles show non-ammotheid families, and coloured branches discriminate ammotheid genera. The numbers at the nodes indicate posterior probabilities greater than 0.5 . Symbols associated with each taxon name indicate the bias in base composition, as expressed by AT (circles) and CG (squares) skews (see main text for details): blue symbols represent a significant positive bias; red symbols indicate a significant negative bias; uncoloured symbols show insignificant values of skews. Asterisks after taxon names indicate holotype specimens. The arrow at the top of the tree shows the connection with Part 2 of the tree (see next page). 


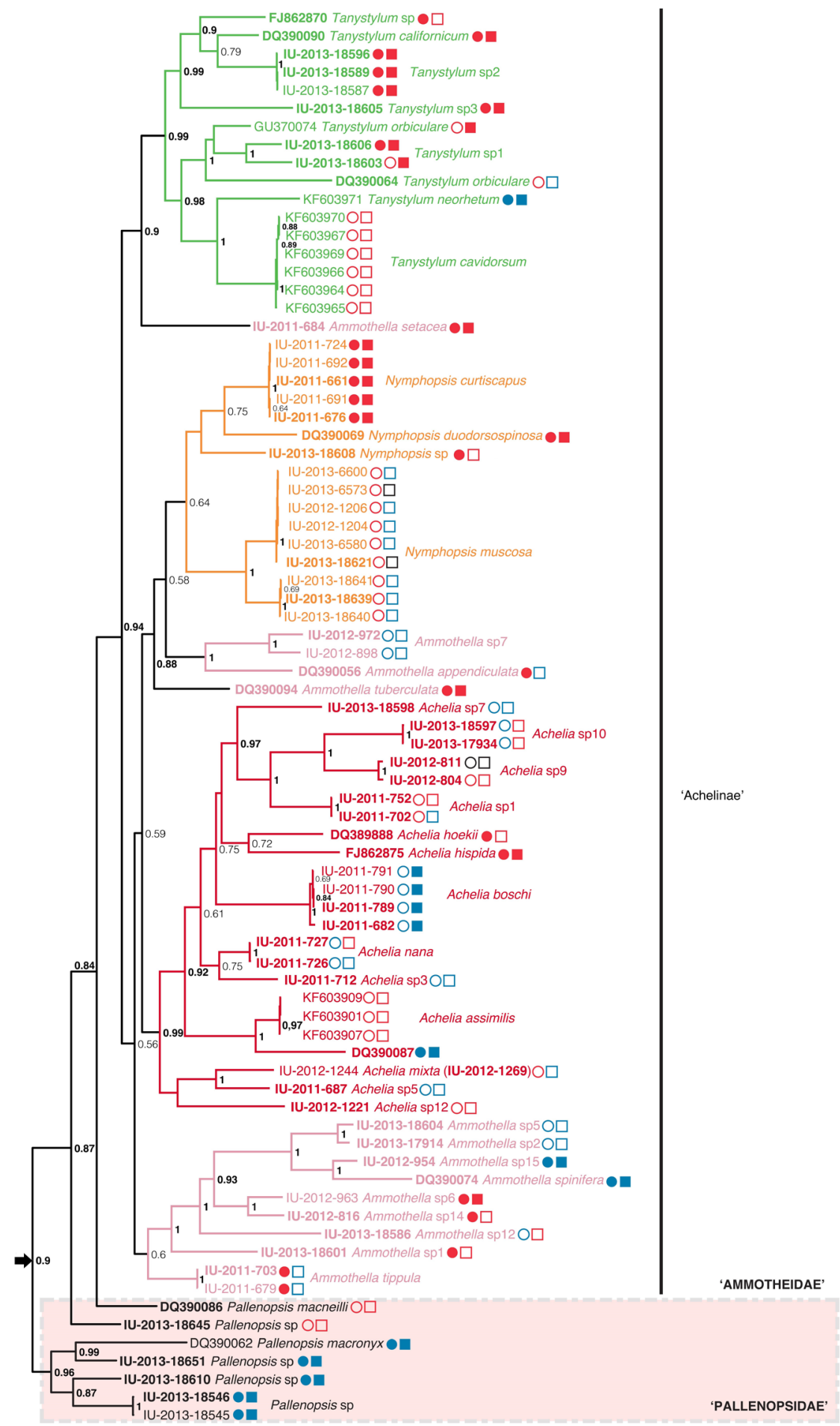

Fig. 3. Part 2, see Part 1 for explanation. 


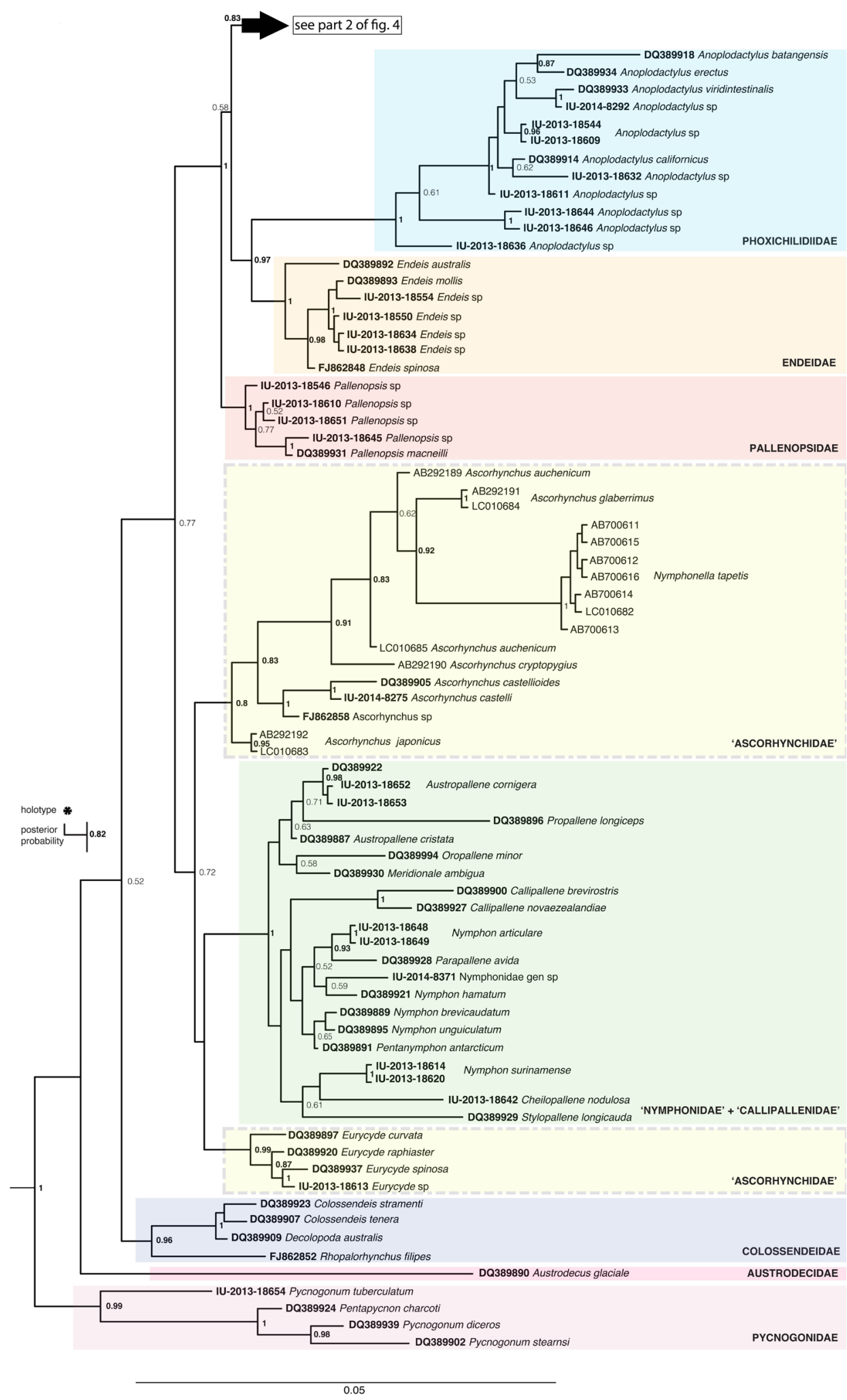

Fig. 4. Bayesian tree of Pycnogonida based on 159 sequences of the nuclear 18S rRNA gene. Coloured rectangles show non-ammotheid families and coloured branches discriminate ammotheid genera. The numbers at the nodes indicate posterior probabilities greater than 0.5. Asterisks after taxon names indicate holotype specimens. Outgroups were removed for better readability. The arrow at the top of the tree shows the connection with Part 2 of the tree (see next page). 


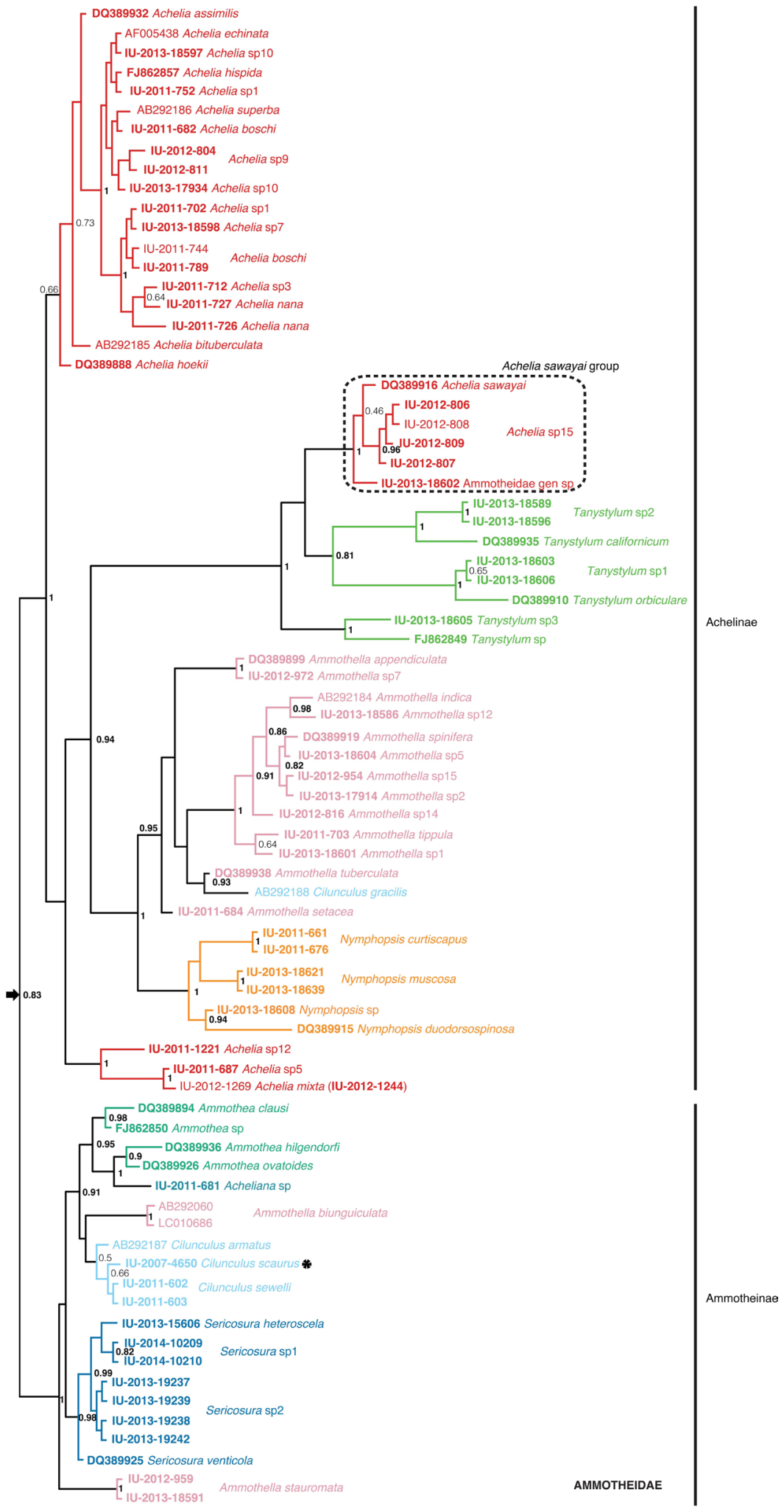

Fig. 4. Part 2, see Part 1 for explanation. 
$(\mathrm{PP}=0.5-0.74)$. In the $18 \mathrm{~S}$ and combined analyses (Figs 4-5, Appendix 2), the "Achelia sawayai group" is included within Achelinae, where it constitutes a strongly supported clade with Tanystylum $(\mathrm{PP}=1)$.

Within Achelinae, the monophyly of Nymphopsis is recovered in all analyses ( $\mathrm{PP}=0.56-0.64$ in CO1 analyses, $\mathrm{PP}=1$ in $18 \mathrm{~S}$ and concatenated analyses). In the CO1+18S tree (Fig. 5), Ammothella s. str. (excluding A. stauromata and A. biunguiculata) constitutes a monophyletic clade ( $\mathrm{PP}=1)$, but the $18 \mathrm{~S}$ tree (Fig. 4) shows that Cilunculus gracilis (which is absent from the CO1 tree) also falls into this clade $(\mathrm{PP}=0.95)$. In the $\mathrm{CO} 1$ analyses (Fig. 3, Appendix 2), Ammothella s. str. is found to be polyphyletic: a first group, which includes Ammothella sp. 7, A. tuberculata Cole, 1904 and A. appendiculata (Dohrn, 1881 ), is related to Nymphopsis with rather strong support ( $\mathrm{PP}=0.6-0.88)$; a second group, which is only represented by the species Ammothella setacea (Helfer, 1938), is close to the genus Tanystylum $(\mathrm{PP}=0.9)$; and a third group, which is composed of Ammothella sp. 1, 2, 6, 12, 14, 15, A. spinifera Cole, 1904 and A. tippula Child, 1983 ( $\mathrm{PP}=0.6$ ), shows an unstable position with respect to other lineages of Achelinae. The monophyly of Achelia s. str. (i.e., excluding the "Achelia sawayai group") is well supported in all analyses ( $\mathrm{PP}=0.92-1)$, except in the $18 \mathrm{~S}$ tree of Fig. 5, where its paraphyly is not found to be robust $(\mathrm{PP}<0.5)$.

Within Ammotheinae, Ammothea is constantly shown as paraphyletic due to the inclusive position of the genus Acheliana $(\mathrm{PP}=1)$ (Figs 3-5, Appendix 2). The genus Cilunculus (excluding C. gracilis) is found to be monophyletic in the $18 \mathrm{~S}$ and $\mathrm{CO} 1+18 \mathrm{~S}$ trees $(\mathrm{PP}=0.95-1)$. The genus Sericosura is monophyletic in all analyses $(\mathrm{PP}=0.97-1)$.

\section{Nucleotide composition in CO1 sequences}

The analysis of third codon positions of the $\mathrm{CO} 1$ gene shows that most families of Pycnogonida are characterized by positive values for AT and CG skews (Fig. 3; detailed values in Supplementary file), which means that their sequences have an excess of A relative to T nucleotides and of $C$ relative to $G$ nucleotides. However, the AT skew is significantly negative in most species of the genus Anoplodactylus Wilson, 1878 (10 on 14), and in Austrodecus glaciale Hodgson, 1907. In the clade grouping Callipallenidae and Nymphonidae, two unrelated species (MNHN-IU-2014-8371 Nymphonidae gen. sp. and Nymphon hamatum) also show negative AT and CG skews. For the family Ammotheidae, our analyses revealed a higher heterogeneity of base composition. The members of the subfamily Achelinae exhibit a strong heterogeneity: for most taxa, the skew values are non-significant (e.g., Nymphopsis and Achelia excluding the "Achelia sawayai group"); Ammothella, Achelia and Tanystylum generally have negative skews, but with some exceptions (Achelia boschi Stock, 1992; A. assimilis (Haswell, 1885); Ammothella spinifera Cole, 1904; Ammothella sp. 15; Tanystylum neorhetum Marcus, 1940 all show positive skews); the "Achelia sawayai group," however, shows a strong positive bias.

\section{Discussion}

\section{Monophyly and low supports of interfamilial relationships}

Both our CO1 and $18 \mathrm{~S}$ analyses supported the monophyly of most pycnogonid families. In contrast, the two families Ammotheidae and Ascorhynchidae were only recovered as monophyletic in the $18 \mathrm{~S}$ trees. In the CO1 trees, the polyphyly of Ammotheidae sensu Bouvier (1923) seems to be robust (but see next paragraph below), whereas the polyphyly of Ascorhynchidae is not highly supported $(\mathrm{PP}<0.6)$. For Ascorhynchidae, the lack of robustness suggests that their basal diversification (i.e., the divergence between Ascorhynchus and Eurycyde) was more ancient than in other families, excepting, perhaps, Ammotheidae (see below). Indeed, for the deepest nodes of the CO1 trees most of the genuine phylogenetic signal has been erased because of the high saturation of synonymous substitutions in the mitochondrial genome and the low levels of variation observed at non-synonymous sites of the CO1 gene (very high selective pressure). This explains why the $\mathrm{CO} 1$ gene did not provide robust support for most interfamilial relationships (Fig. 5). The sole exception concerns Callipallenidae and Nymphonidae, 
Fig. 5. Bayesian tree of Pycnogonida obtained from the concatenation of $\mathrm{CO} 1$ and $18 \mathrm{~S}$ genes (135 taxa). Coloured rectangles show nonammotheid families and coloured branches discriminate ammotheid genera. The numbers at the nodes indicate posterior probabilities greater than 0.5. Bold branches indicate $\mathrm{CO} 1$ (yellow), 18S (blue), or both (red) support in the independent analyses of $\mathrm{CO} 1$ and $18 \mathrm{~S}$ genes provided in Appendix 1. Asterisks after taxon names indicate holotype specimens. Outgroups were removed for better readability.

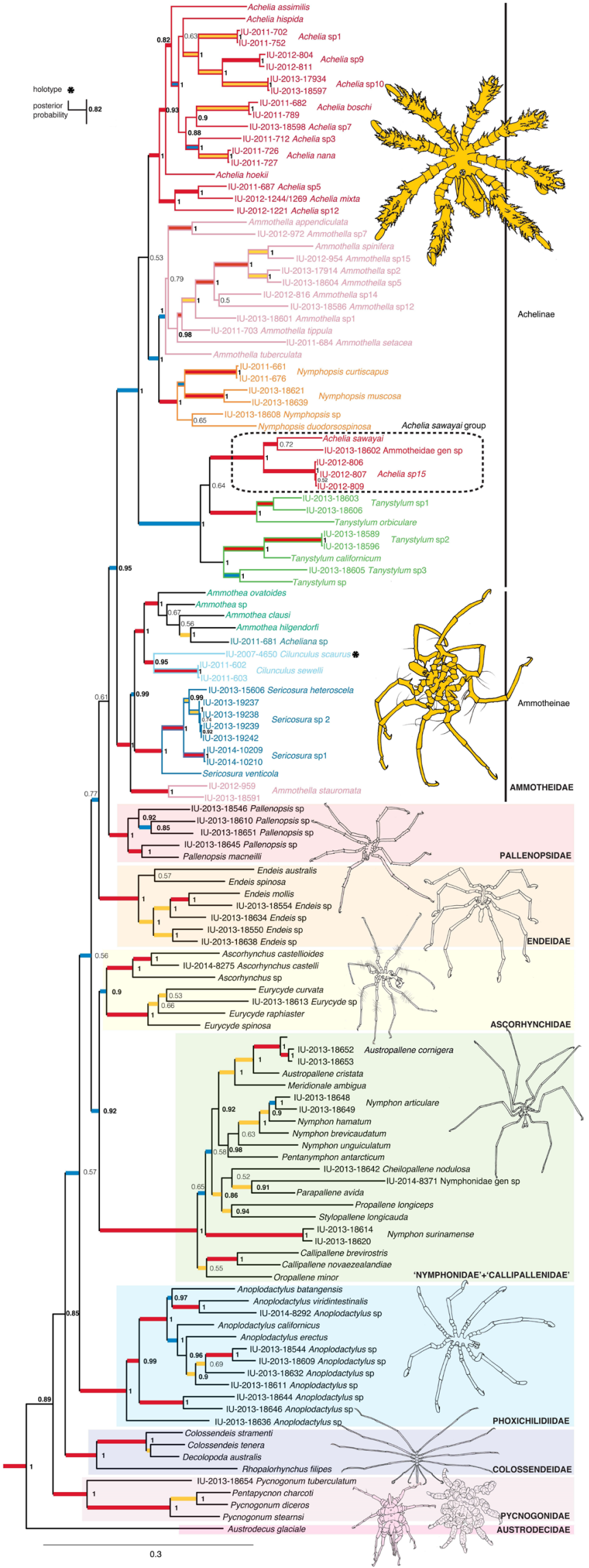


which are grouped together at the end of a very long branch in the CO1 and CO1+18S trees (Figs 3, 5). This result clearly indicates that the divergence between Callipallenidae and Nymphonidae is more recent than that of other families. In agreement with this view, they share many morphological characters, including the structure of the 10-articled ovigers and the presence of well-developed chelae (Bamber 2007b). In addition, our datasets did not provide any evidence for their reciprocal monophyly. On the contrary, our analyses suggested that these two families are reciprocally polyphyletic $(\mathrm{PP}<0.92)$. However, we found very different polyphyletic patterns in the combined, $\mathrm{CO} 1$ and $18 \mathrm{~S}$ analyses (Figs 3-5), which suggests that $\mathrm{CO} 1$ and/or 18S genes are not the best markers to resolve relationships at this level of the pycnogonid tree (Figs 3-4, Appendix 2).

Even with the $18 \mathrm{~S}$ dataset, most basal relationships within Pycnogonida were not well-resolved, suggesting that most families of Pycnogonida have diverged rapidly from each other. As pointed out by Charbonnier et al. (2007), there is a substantial hiatus in the fossil record of Pycnogonida, between the Devonian (ca $400 \mathrm{Mya}$ ) and the Jurassic (ca $160 \mathrm{Mya}$ ), and the concomitant appearance of several different families during the Mesozoic is in agreement with a crown group radiation. To explain both the lack of resolution for interfamilial relationships and the long branch that separates outgroups from pycnogonids, Arabi et al. (2010) have also suggested that a very long period of time occurred between the origin of Pycnogonida, and the subsequent rapid diversification that led to extant families.

\section{Strong heterogeneity in base composition in the $\mathrm{CO1}$ gene of Ammotheidae}

The analyses of CO1 and 18S genes revealed real discordance regarding the phylogeny of Ammotheidae. In the $18 \mathrm{~S}$ tree (Fig. 4), the family Ammotheidae is found to be monophyletic and it can be divided into two major clades corresponding to the subfamilies Ammotheinae and Achelinae. In the CO1 tree (Fig. 3), the family appears to be polyphyletic: most species of Achelinae fall into the paraphyletic Pallenopsidae, whereas those of the "Achelia sawayai group" are related to the Endeidae, the Ammotheinae being their sister group. As exposed in detail below, we suggest that the apparent topological conflict between $\mathrm{CO} 1$ and $18 \mathrm{~S}$ markers is the consequence of the combined effects of mutational saturation and multiple changes in base composition during the mtDNA evolution of Ammotheidae.

Previous studies have shown that in most species of Metazoa, the double-stranded and circular mitochondrial genome presents a typical strand asymmetry, in which synonymous sites of the positive strand are characterized by an excess of A relative to $\mathrm{T}$ nucleotides and of $\mathrm{C}$ relative to $\mathrm{G}$ nucleotides (i.e., positive AT and CG skews), while synonymous sites of the complementary negative strand show a reverse bias. This strand-bias in base composition is the consequence of asymmetric mutational constraints during replication and/or transcription of the mtDNA genome (Hassanin et al. 2005; Hassanin 2006). Hassanin et al. (2005) have suggested that the orientation of the control region of the mtDNA is crucial in the establishment of asymmetric mutational constraints, because this region contains both replication and transcription origins. In support of that hypothesis, they showed that two kinds of mitogenomic inversions can lead to a reversal in nucleotide composition: (1) inversion of the control region can result in a global reversal of asymmetric mutational constraints; (2) inversion of a genomic fragment can result in a local reversal of asymmetric mutational constraints. Several reversals of strand specific bias were identified in CO1 sequences of Chelicerata (Arabi et al. 2010, 2012) including the common ancestors of Scorpiones and Opisthothelae spiders, as well as several taxa within Acari, Opiliones, Pseudoscorpiones and Pycnogonida. Within Pycnogonida, Arabi et al. (2010, 2012) have revealed a strong heterogeneity in base composition, particularly among ammotheids, with taxa characterized by positive AT and CG skews (Achelia assimilis), positive CG skew but no significant bias for AT (Ammothea), negative AT and CG skews (e.g., Achelia hispida Hodge, 1864, Ammothella tuberculata and Nymphopsis duodorsospinosa Hilton, 1942) and negative AT skew but no significant bias for CG (Ammothella appendiculata). Our analyses showed that the situation is even more complex with the detection of two additional categories: taxa with no significant strand-bias (e.g., Nymphopsis) 
and taxa with negative CG skew but no significant bias for AT (e.g., Tanystylum orbiculare Wilson, 1878). More importantly, our analyses of base composition in CO1 sequences suggest that the apparent polyphyly of Ammotheidae and that of Achelinae resulted from artefacts in tree reconstruction, because Ammotheinae, Achelinae s. str. (excluding the "Achelia sawayai group") and the "Achelia sawayai group" exhibit clear differences in base composition. Indeed, many species of Achelinae excluding the "Achelia sawayai group" are characterized by one or two negative skews in their CO1 sequence. Only four species of this large clade appear to be characterized by positive AT and CG skews (Achelia assimilis, Ammothella sp. $15+$ A. spinifera, and Tanystylum neorhetum), and all of them occupy a derived position within the subfamily. As a consequence, we can infer that the $\mathrm{CO} 1$ sequence of the most recent common ancestor of Achelinae was characterized by a negative AT skew and a negative or non-significant CG skew. In contrast, all species of the "Achelia sawayai group" clade have positive AT and CG skews, and those of the Ammotheinae clade generally show a positive CG skew associated with a non-significant AT skew. As pointed out in previous studies, important differences in base composition of mtDNA genes may be misleading for phylogenetic inferences, because they can produce artefacts such as Long Branch Attraction (LBA), when distantly related taxa with similar base composition tend to group together, or the opposite, Long Branch Repulsion (LBR), when closely related taxa with reverse strand-specific biases do not group together (Hassanin et al. 2005; Hassanin 2006; Arabi et al. 2010, 2012).

Here, we suggest that the CO1 polyphyly of Achelinae and Ammotheidae can be explained by both LBA and LBR artefacts, because two groups of Achelinae have very different base compositions, and because each of them tends to be attracted by the taxa with the most similar strand-specific bias, i.e., Endeidae for the "Achelia sawayai group" and Pallenopsis macneilli Clark, 1963 for all other species of Achelinae, resulting in the apparent polyphyly of Achelinae and Ammotheidae. This effect is particularly misleading for Ammotheidae because their diversification is assumed to be ancient, as revealed by their remarkable morphological diversity and by our analyses of $18 \mathrm{~S}$ and $\mathrm{CO} 1$ genes (up to $25 \%$ divergence between ammotheid $\mathrm{CO} 1$ sequences). In this context, and given that the $18 \mathrm{~S}$ gene is more appropriate for studying the deepest nodes of arthropod classes (e.g., Mallatt et al. 2004; Arabi et al. 2012), we conclude that our nuclear gene gave accurate information for the monophyly of Ammotheidae, Ammotheinae and Achelinae. Morphologically, all representatives of Ammotheidae sensu Bouvier (1923) share the structure of the ovigers with feeble strigilis, without rows of compound spines, and generally without terminal claw. The grouping of Achelia, Ammothella s. str., Nymphopsis and Tanystylum in the subfamily Achelinae also makes sense from a purely morphological perspective. Indeed, Ammothella s. str. and Nymphopsis, which are shown as sister-groups in our study, share a lot of characters (long abdomen, eventually bi-articulated and trumpet-like scapes, long ocular tubercle), while Achelia and Tanystylum share a discoidal body outline.

\section{Taxonomic implications}

Only two ammotheid genera, Nymphopsis and Sericosura, are found to be monophyletic. Interestingly, specimens of Sericosura from the Pacific (Sericosura sp. 1 and S. venticola Child, 1987) occupy a paraphyletic position with respect to the Atlantic specimens (Sericosura sp. 2 and S. heteroscela Child \& Segonzac, 1996). This pattern is coherent with the biogeographic model proposed by Bachraty et al. (2009), in which they suggested that most hydrothermal vent taxa have dispersed from the Pacific into the North Atlantic Ocean by a deep-sea corridor that stayed open until the closure of the Panama Isthmus around 3 million years ago.

The genus Achelia is polyphyletic: most species are grouped into a robust clade, whereas the "Achelia sawayai group" is placed within the genus Tanystylum. However, the paraphyly of Tanystylum was not highly supported by the $18 \mathrm{~S}$ dataset, suggesting that the hypothesis of monophyly cannot be excluded. Although Achelia and Tanystylum share some superficial similarities, the latter genus shows a typical morphology characterized by palps with a reduced number of articles. Therefore, we consider that 
further studies are needed to decide whether a new genus should be described for members of the "Achelia sawayai group".

The inclusive position of Acheliana within the genus Ammothea suggests that Acheliana should be synonymized with Ammothea. This result was partially perceived by Arnaud (1971a), who noted the close relationship between the two genera. However, the type species of Acheliana, A. tropicalis Arnaud, 1971, must be re-examined to provide a definitive conclusion.

The genus Cilunculus is polyphyletic in the $18 \mathrm{~S}$ tree, because the species $C$. gracilis is included within Ammothella. Misidentification is rather unlikely, as the $18 \mathrm{~S}$ sequence of $C$. gracilis was produced by Nakamura et al. (2007), who described the species with Child in 1991 (Nakamura \& Child 1991). A taxonomic issue is a more plausible explanation. Indeed, C. gracilis is one of the seven species of Cilunculus presenting a two-jointed scape, a characteristic shared with all species of the genus Ammothella. Nakamura \& Child (1991) themselves recognized that C. gracilis was closely allied to Ammothella. Its assignation to the genus Cilunculus was based on the presence of a (shallow) hood-like extension of the head above the chelifores and the proboscis (Loman 1908). However, according to Child (1994), this is the only character to "temporarily" support a genus (Cilunculus) which "hangs rather precariously over the pit of synonymy", and Nakamura et al. (2007) also expressed the unclearness of this character for several species. Now, it is becoming obvious that a revision of the genus Cilunculus is urgently needed, as our results confirmed that the presence of a cephalic hood is not a reliable character for diagnosing members of this taxon. As there is no reason to wait to reassign the currently discussed species to the genus Ammothella, we refer to it as Ammothella gracilis (Nakamura \& Child, 1991) comb. nov. The status of other species of Cilunculus with two-jointed scapes and shallow hoods will probably follow the same reassignment in forthcoming revisions.

The genus Ammothella is polyphyletic in all analyses, as most species are clustered into the Achelinae, whereas A. stauromata, and potentially A. biunguiculata (according to $18 \mathrm{~S}$ data), are robustly placed in the Ammotheinae. From a morphological point of view, both latter species possess the typical characters of the genus Ammothella, but A. biunguiculata shows a very original profile with short chelifores and short abdomen (see Dohrn 1881; Bouvier 1923; Hedgpeth 1941), and A. stauromata is easily recognizable, with its characteristic dorso-median tubercles (see Child 1982; Fig. 6A, C). Therefore, both molecular and morphological data suggest that the taxonomic status of these two species must be revised. For A. biunguiculata, no taxonomic change can be proposed here because we do not have morphological material and the CO1 sequence is not available. For A. stauromata, however, we can describe a new genus, maybe provisional, as there is no evidence for a relationship with any other described genus. Thus, this taxon must receive due attention in future studies.

Family Ammotheidae Dohrn, 1881

Subfamily Ammotheinae Dohrn, 1881 emend.

Teratonotum gen. nov. urn:1sid:zoobank.org:act:CD6D82C7-E0EC-4E46-A2C6-559678E48B29

Fig. 6

\section{Type species}

Ammothella stauromata Child, 1982: 270 (in list), 271-273, fig. 1.

Ammothella stauromata - Arango 2003a: 2730-2731. - Bamber 2004: 2-3, 21 (in tab.); 2007a: 256 (in list). - Child 1987: 180 (in list); 1988: III (in list), 5-7, 30-31 (in list); 1990: 316 (in description); 1996: 544; 1998: 290-291. — Müller 1989: 125; 1990a: 66; 1990b: 106. — Nakamura \& Child 1988: 809-810. — Stock 1994: 29. 

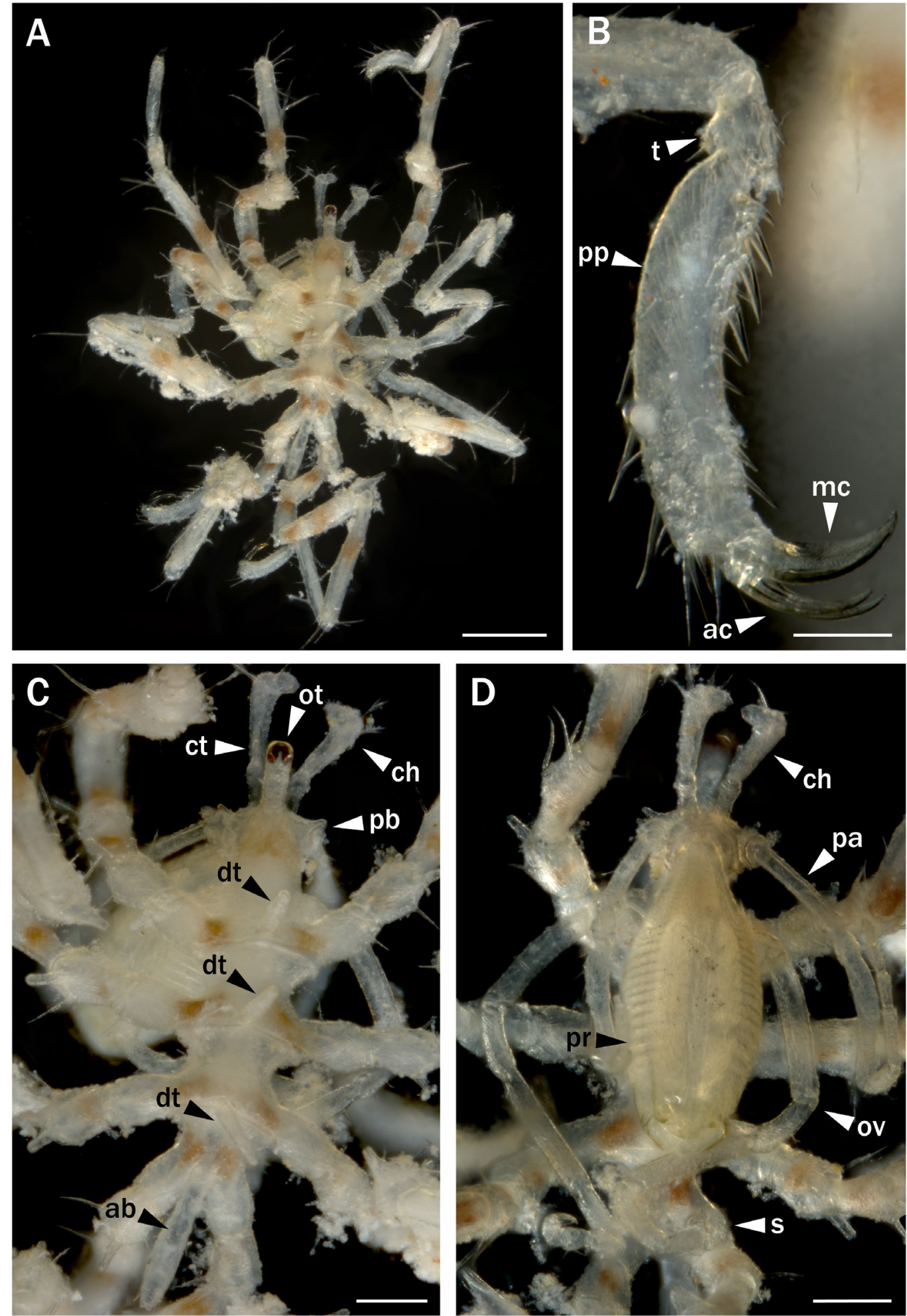

Fig. 6. Teratonotum stauromatum (Child, 1982) gen. et comb. nov. (MNHN-IU-2013-17964). A. Dorsal view. B. Propodus of third leg. C. Dorsal view of body. D. Ventral view of body. Abbreviations: $a b=$ abdomen; $a c=$ auxiliary claw; $c h=$ chelifore; $c t=$ chelifore tubercle on the anterior tip of the first scape; $d t=$ dorsal tubercle; $m c=$ main claw; $o t=$ ocular tubercle; $o v=$ oviger; $p a=$ palp; $p b=$ bulbous tubercle bearing the palp; $p p=$ propodus; $p r=$ proboscis; $s=$ strigilis; $t=$ tarsus. Scale bars: $\mathrm{A}=0.5 \mathrm{~mm} ; \mathrm{B}=0.1 \mathrm{~mm}$; $\mathrm{C}-\mathrm{D}=0.2 \mathrm{~mm}$. 


\section{Diagnosis}

Trunk slender, totally segmented; ocular tubercle present, with three long, slender dorso-median tubercles; abdomen long, straight, almost vertical; scapes bi-articled, more proximal article with dorsodistal slender tubercle, chelae atrophied in adult; palps 9-articulated, originating from bulbous tubercles (with slender tubercle) placed anterolaterally on cephalic segment; oviger 10-articulated, originating ventral to first lateral processes, strigilis with denticulate spines; third leg with a single cement tube at anterior tip in males, tarsus short, propodus curved, auxiliary claws present.

\section{Etymology}

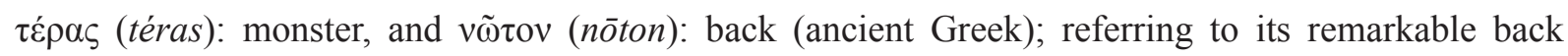
tubercles. Gender neutral.

\section{An underestimated biodiversity}

The CO1 data generated in this study on specimens collected during the recent MNHN expeditions indicate that the diversity of Ammotheidae was poorly represented in the nucleotide databases, such as GenBank and BOLD (Ratnasingham \& Hebert 2007). Indeed, all our new CO1 sequences show at least $7 \%$ of nucleotide divergence with the ca 430 pycnogonid sequences available in GenBank, and even up to $11 \%$ if the genus Sericosura is excluded from the comparisons. This means that none of the ammotheids analysed here can be identified at the species level using molecular barcoding. Actually, this result is not surprising if we consider that most of the pycnogonids previously registered in the GenBank and BOLD databases were collected along the coastlines of temperate South America (Chile and Argentina) and Antarctica (Fig. 1), whereas our specimens come from widely spread geographic areas, i.e., French Guiana, Guadeloupe, Madagascar, Marquesas Islands, New Caledonia, Papua New Guinea, Vanuatu, and Atlantic and Pacific vents (Fig. 2). Besides, another issue for molecular taxonomy is the fact that most of the barcode sequences deposited in BOLD were not identified to the family level (958 of 1315, 72.85\%). Beyond a problem of molecular taxonomy, ammotheids, and more generally pycnogonids, suffer from a lack of knowledge. For instance, our specimens collected along the coastlines of southern Madagascar show a far more rich diversity than previously recorded in the literature: five different species of Achelia were identified, whereas only two species were previously known from Madagascar; none of the species of Ammothella and Endeis studied here were known in the region; and a new species of Acheliana was found (Arnaud 1971a, 1971b, 1972, 1973; Stock 1974). In a more general way, it seems that the large collection of sea spiders assembled during the MNHN expeditions represents an important input to our knowledge of this group and promises the description of numerous new species (in prep.).

\section{Acknowledgements}

The studied specimens were collected during MNHN expeditions of the programs "Tropical Deep Sea Benthos" and "Planète Revisitée" (http://laplaneterevisitee.org). Deep-sea specimens were mainly collected during the many cruises organized by P. Bouchet, S. Samadi and L.C. of the MNHN and Institut de Recherche pour le Developpement (IRD). Recent expeditions were funded by the Total Foundation, the Prince Albert II of Monaco Foundation, the Sloan Foundation, the Stavros Niarchos Foundation and conducted by the MNHN and Pro-Natura International. The KARUBENTHOS expedition was sponsored via European funding (FEDER), the Port Autonome de la Guadeloupe (PAG). Specimens from hydrothermal vents were provided by the IFREMER:BICOSE and FUTUNA 3 cruises (financial support was provided by the Eramet and Technip companies). The CEAMARC cruise on RSV Aurora Australis was funded by the Australian Antarctic Division, the French polar institute IPEV, CNRS and the ANR project ANTFLOCKs (G. Lecointre). Special thanks to S. Hourdez for the specimens from the Hydromar cruise, to N. Schnell for photography and to the editor and the two anonymous reviewers for useful comments on the first version of the manuscript. R.S. acknowledges the French-Taiwanese 
grant TF-DeepEvo co-funded by the ANR and the Ministry of Science and Technology of Taiwan for supporting his visit to Germany. This work was supported by the project "Taxonomie moléculaire: DNA Barcode et Gestion durable des Collections", funded by the MNHN and the "Bibliothèque du Vivant" network funded by the CNRS, MNHN, INRA and CEA (Genoscope).

\section{References}

Arabi J., Cruaud C., Couloux A. \& Hassanin A. 2010. Studying sources of incongruence in arthropod molecular phylogenies: sea spiders (Pycnogonida) as a case study. Comptes Rendus Biologies 333 (5): 438-453. http://dx.doi.org/10.1016/j.crvi.2010.01.018

Arabi J., Judson M.L., Deharveng L., Lourenço W.R., Cruaud C. \& Hassanin A. 2012. Nucleotide composition of $\mathrm{CO} 1$ sequences in Chelicerata (Arthropoda): detecting new mitogenomic rearrangements. Journal of Molecular Evolution 74 (1-2): 81-95. http://dx.doi.org/10.1007/s00239-012-9490-7

Arango C.P. 2003a. Sea spiders (Pycnogonida, Arthropoda) from the Great Barrier Reef, Australia: new species, new records and ecological annotations. Journal of Natural History 37: 2723-2772. http:// dx.doi.org/10.1080/00222930210158771

Arango C.P. 2003b. Molecular approach to the phylogenetics of sea spiders (Arthropoda: Pycnogonida) using partial sequences of nuclear ribosomal DNA. Molecular Phylogenetics and Evolution 28 (3): 588-600. http://dx.doi.org/10.1016/S1055-7903(03)00069-1

Arango C.P. \& Wheeler W.C. 2007. Phylogeny of the sea spiders (Arthropoda, Pycnogonida) based on direct optimization of six loci and morphology. Cladistics 23 (3): 255-293. http://dx.doi.org/10.1111/ j.1096-0031.2007.00143.x

Arango C.P., Soler-Membrives A. \& Miller K.J. 2011. Genetic differentiation in the circum-Antarctic sea spider Nymphon australe (Pycnogonida: Nymphonidae). Deep Sea Research II 58 (1): 212-219. http://dx.doi.org/10.1016/j.dsr2.2010.05.019

Arnaud F. 1971a. Acheliana tropicalis n. gen., n. sp., pycnogonide des récifs coralliens du sud-ouest de Madagascar. Beaufortia 18 (241): 199-204.

Arnaud F. 1971b. Pycnogonides des récifs coralliens de Madagascar. 2. Redescription de Pycnogonum madagascariensis Bouvier, 1911. Téthys 1: 161-64.

Arnaud F. 1972. Pycnogonides des récifs coralliens de Madagascar. 3. Famille des Callipallenidae. Téthys 3: 157-64.

Arnaud F. 1973. Pycnogonides des récifs coralliens de Madagascar. 4. Colossendeidae, Phoxichilidiidae et Endeidae. Téthys 4 (4): 953-960.

Arnaud F. \& Bamber R.N. 1987. The biology of Pycnogonida. Advances in Marine Biology 24: 1-96. http://dx.doi.org/10.1016/S0065-2881(08)60073-5

Bachraty C., Legendre P. \& Desbruyères D. 2009. Biogeographic relationships among deep-sea hydrothermal vent faunas at global scale. Deep Sea Research I 56 (8): 1371-1378. http://dx.doi. org/10.1016/j.dsr.2009.01.009

Bamber R.N. 2004. Pycnogonids (Arthropoda: Pycnogonida) from French cruises to Melanesia. Zootaxa 551: 1-27.

Bamber R.N. 2007a. Pycnogonida of New Caledonia. In: Payri C.E. \& Richer de Forges B. (eds) Compendium of Marine Species of New Caledonia: 255-257. Documents Scientifiques et Techniques, deuxième édition, IRD Nouméa 117.

Bamber R.N. 2007b. A holistic re-interpretation of the phylogeny of the Pycnogonida Latreille, 1810 (Arthropoda). Zootaxa 1668: 295-312. 
Bamber R.N., El Nagar A. \& Arango C. (eds) 2015. Pycnobase: World Pycnogonida Database. Available from http://www.marinespecies.org/pycnobase $\% 20$ on $\% 20$ [accessed 2 Nov. 2015].

Benson D. A., Clark K., Karsch-Mizrachi I., Lipman D.J., Ostell J. \& Sayers E.W. 2015. GenBank. Nucleic Acids Research 43 (D1): D30-D35. http://dx.doi.org/10.1093/nar/gku1216

Bouchet P., Héros V., Lozouet P. \& Maestrati P. 2008. A quarter-century of deep-sea malacological exploration in the South and West Pacific: Where do we stand? How far to go? In: Héros V., Cowie R.H. \& Bouchet P. (eds) Tropical Deep-Sea Benthos 25: 9-40. Mémoires du Muséum national d'Histoire naturelle 196.

Bouvier E.-L. 1910. Les Pycnogonides à cinq paires de pattes recueillis par la mission antarctique Jean Charcot à bord du Pourquoi Pas? Comptes Rendus des Séances Hebdomadaires de l'Académie des Sciences, Paris 142: 15-22.

Bouvier E.-L. 1923. Pycnogonides. Faune de France 7: 1-69.

Charbonnier S., Vannier J. \& Riou B. 2007. New sea spiders from the Jurassic La Voulte-sur-Rhône Lagerstätte. Proceedings of the Royal Society of London B 274 (1625): 2555-2561. http://dx.doi. org/10.1098/rspb.2007.0848

Child C.A. 1982. Pycnogonida from the Western Pacific Islands, I. The Marshall Islands. Proceedings of the Biological Society of Washington 95 (2): 270-281.

Child C.A. 1987. Chapter 16. Pycnogonida of Enewetak Atoll. In: Devaney D.M., Reese E.S., Burch B.L. \& Helfrich P. (eds) The Natural History of Enewetak Atoll 2: 179-180. Hawaii, United States Department of Energy, Office of Energy Research, Office of Health and Environmental Research, Ecological Research Division.

Child C.A. 1988. Pycnogonida of the Western Pacific Islands, III: Recent Smithsonian-Philippine expeditions. Smithsonian Contributions to Zoology 468 (1-4): 1-32. http://dx.doi.org/10.5479/ $\underline{\text { si.00810282.468 }}$

Child C.A. 1990. Pycnogonida of the Western Pacific Islands, VIII: Recent collections from islands of the Great Barrier Reef, Australia. Proceedings of the Biological Society of Washington 103 (2): 311-335.

Child C.A. 1994. Antarctic and Subantarctic Pycnogonida. 1. The Family Ammotheidae. Washington, DC. Biology of the Antarctic Seas 23: 1-48. http://dx.doi.org/10.1029/AR063p0001

Child C.A. 1996. Pycnogonida of the Western Pacific Islands, XIII: Collections from Indonesia, Melanesia, and Micronesia. Oceanographic Literature Review 4 (44): 366.

Child, C. A. 1998. Pycnogonida of the Western Pacific Islands, XIV: A shallow-water collection from Tonga. Species Diversity 3 (2): 289-300.

Dietz L., Arango C.P., Dömel J.S., Halanych K.M., Harder A.M., Held C., Mahon A.R., Mayer C., Melzer R.R., Rouse G.W., Weis A., Wilson N.G. \& Leese F. 2015. Regional differentiation and extensive hybridization between mitochondrial clades of the Southern Ocean giant sea spider Colossendeis megalonyx. Royal Society Open Science 2 (7): e140424. http://dx.doi.org/10.1098/rsos.140424

Dohrn A. 1881. Die Pantopoden des Golfes von Neapel und der angrenzenden Meeres-Abschnitte. Monographie der Fauna und Flora des Golfes von Neapel 3: 1-252.

Fry W.G. 1978. A classification within the pycnogonids. Zoological Journal of the Linnean Society 63 (1-2): 35-58. http://dx.doi.org/10.1111/j.1096-3642.1978.tb02089.x

Griffiths H.J., Arango C.P., Munilla T. \& McInnes S.J. 2011. Biodiversity and biogeography of Southern Ocean pycnogonids. Ecography 34 (4): 616-627. http://dx.doi.org/10.1111/j.1600-0587.2010.06612.x 
Hassanin A. 2006. Phylogeny of Arthropoda inferred from mitochondrial sequences: strategies for limiting the misleading effects of multiple changes in pattern and rates of substitution. Molecular Phylogenetics and Evolution 38 (1): 100-116. http://dx.doi.org/10.1016/j.ympev.2005.09.012

Hassanin A., Léger N. \& Deutsch J. 2005. Evidence for multiple reversals of asymmetric mutational constraints during the evolution of the mitochondrial genome of Metazoa, and consequences for phylogenetic inferences. Systematic Biology 54 (2): 277-298. http://dx.doi.org/10.1080/10635150590947843

Hedgpeth J.W. 1941. A key to the Pycnogonida of the Pacific coast of North America. Transactions of the San Diego Society of Natural History 9 (26): 253-264. Available from http://biodiversitylibrary.org/ page/5715977 [accessed 28 Jan. 2017].

Hedgpeth J.W. 1948. The Pycnogonida of the Western North Atlantic and the Caribbean. Proceedings of the United States Museum 97 (3216): 157-342.

Hoek P.P.C. 1881. Nouvelles études sur les pycnogonides. Archives de Zoologie Expérimentale et Générale 9: 445-542.

Krabbe K., Leese F., Mayer C., Tollrian R. \& Held C. 2010. Cryptic mitochondrial lineages in the widespread pycnogonid Colossendeis megalonyx Hoek, 1881 from Antarctic and Subantarctic waters. Polar Biology 33 (3): 281-292. http://dx.doi.org/10.1007/s00300-009-0703-5

León T.M. 2001. Synopsis of the pycnogonids from Antarctic and Subantarctic waters. Polar Biology 24: 941-945. http://dx.doi.org/10.1007/s003000100305

Loman J.C. 1908. Die Pantopoden der Siboga-Expedition. Siboga Expedition 40: 1-88.

Mallatt J.M., Garey J.R. \& Shultz J.W. 2004. Ecdysozoan phylogeny and Bayesian inference: first use of nearly complete $28 \mathrm{~S}$ and $18 \mathrm{~S}$ rRNA gene sequences to classify the arthropods and their kin. Molecular Phylogenetics and Evolution 31(1): 178-191. http://dx.doi.org/10.1016/j.ympev.2003.07.013

Müller H.-G. 1989. Shallow-water Pycnogonida from coral reefs at Moorea, Society Islands, with description of Rhynchothorax tiahurensis n. sp. Bonner Zoologische Beiträge 40 (2): 123-139.

Müller H.-G. 1990a. Shallow-water Pycnogonida from Kenya and Sri Lanka, with descriptions of three new species. Bonner Zoologische Beiträge 41 (1): 63-79.

Müller H.-G. 1990b. On some Indo-West-Pacific Pycnogonida from the Zoologisk Museum, Copenhagen. Zoologische Abhandlungen, Staatliches Museum für Tierkunde Dresden 45 (10): 103-110.

Munilla T. \& Soler-Membrives A. 2009. Check-list of the pycnogonids from Antarctic and sub-Antarctic waters: zoogeographic implications. Antarctic Science 21 (2): 99-111. http://dx.doi.org/10.1017/ $\underline{\text { S095410200800151X }}$

Munilla T. \& Soler-Membrives A. 2015. Pycnogonida from the Bellingshausen and Amundsen seas: taxonomy and biodiversity. Polar Biology 38 (3): 413-430. http://dx.doi.org/10.1007/s00300-014$\underline{1585-8}$

Nakamura K. \& Child A.C. 1988. Pycnogonida of the western Pacific Islands. V. A collection by the Kakuyo Maru from Samoa. Proceedings of the Biological Society of Washington 101 (4): 809-816. https://dx.doi.org/10.5479/si.00810282.512

Nakamura K. \& Child C.A. 1991. Pycnogonida from waters adjacent to Japan. Smithsonian Contributions to Zoology 512 (1-4): 1-74.

Nakamura K., Kano Y., Suzuki N., Namatame T. \& Kosaku A. 2007. 18S rRNA phylogeny of sea spiders with emphasis on the position of Rhynchothoracidae. Marine Biology 153 (2): 213-223. http:// dx.doi.org/10.1007/s00227-007-0803-0

Posada D. 2008. jModelTest: phylogenetic model averaging. Molecular Biology and Evolution 25 (7): 1253-1256. http://dx.doi.org/10.1093/molbev/msn083 
Rambaut A. 2002. Sequence Alignment Editor, version 2.0 alpha 11. Available from http://www.evolve. zoo.ox.ac.uk/ [accessed 28 Jan. 2017].

Ratnasingham S. \& Hebert P.D. 2007. BOLD: The Barcode of Life Data System. Molecular Ecology Notes 7 (3): 355-364. http://dx.doi.org/10.1111/j.1471-8286.2007.01678.x

Regier J.C., Shultz J.W., Zwick A., Hussey A., Ball B., Wetze R., Martin J.W. \& Cunningham C.W. 2010. Arthropod relationships revealed by phylogenomic analysis of nuclear protein-coding sequences. Nature 463 (7284): 1079-1083. http://dx.doi.org/10.1038/nature08742

Rehm P., Meusemann K., Borner J., Misof B. \& Burmester T. 2014. Phylogenetic position of Myriapoda revealed by 454 transcriptome sequencing. Molecular Phylogenetics and Evolution 77: 25-33. http:// dx.doi.org/10.1016/j.ympev.2014.04.007

Richer de Forges B., Chan T.-Y., Corbari L., Lemaitre E., Macpherson E., Ahyong S.T. \& Ng P.K.L. 2013. The MUSORSTOM-TDSB deep sea benthos exploration programme (1976-2012): An overview of crustacean discoveries and new perspectives on deep-sea zoology and biogeography. In: Ahyong A., Chan T.-Y., Corbari L. \& Ng P.K.L. (eds) Tropical Deep-Sea Benthos vol. 27: 13-66. Muséum national d'Histoire naturelle, Paris.

Roeding F., Borner J., Kube M., Klages S., Reinhardt R. \& Burmester T. 2009. A 454 sequencing approach for large scale phylogenomic analysis of the common emperor scorpion (Pandinus imperator). Molecular Phylogenetics and Evolution 53 (3): 826-834. http://dx.doi.org/10.1016/j.ympev.2009.08.014

Ronquist F.R. \& Huelsenbeck J.P. 2003. MRBAYES: Bayesian phylogenetic inference under mixed models. Bioinformatics 19 (12): 1572-1574. http://dx.doi.org/10.1093/bioinformatics/btg180

Schiaparelli S., Oliverio M., Taviani M., Griffiths H., Lörz A.N. \& Albertelli G. 2008. Circumpolar distribution of the pycnogonid-ectoparasitic gastropod Dickdellia labioflecta (Dell, 1990) (Mollusca: Zerotulidae). Antarctic Science 20 (5): 497-498. http://dx.doi.org/10.1017/S0954102008001302

Spalding M.D., Fox H.E., Allen G.R., Davidson N., Ferdaña Z.A., Finlayson M., Halpern B.S., Jorge M.A., Lombana A., Lourie S.A., Martin K.D., McManus E., Molnar J., Recchia C.A. \& Robertson J. 2007. Marine ecoregions of the world: a bioregionalization of coastal and shelf areas. BioScience 57 (7): 573-583. http://dx.doi.org/10.1641/B570707

Stephensen K.H. 1933. Havedderkopper (Pycnogonida) og rankefødder (Cirripedia). Danmarks Fauna 38: $1-158$.

Stock J.H. 1974. Medio- and infralittoral Pycnogonida collected during the IIOE near the landbase on Nossi-Be, Madagascar. Bulletin Zöologisch Museum 4 (3): 11-18.

Stock J.H. 1994. Indo-west Pacific Pycnogonida collected by some major oceanographic expeditions. Beaufortia 44 (3): 17-77.

Manuscript received: 15 February 2016

Manuscript accepted: 29 October 2016

Published on: 24 February 2017

Guest editors: Line Le Gall, Frédéric Delsuc, Stéphane Hourdez, Guillaume Lecointre

and Jean-Yves Rasplus

Desk editor: Danny Eibye-Jacobsen

Printed versions of all papers are also deposited in the libraries of the institutes that are members of the EJT consortium: Muséum national d'Histoire naturelle, Paris, France; Botanic Garden Meise, Belgium; Royal Museum for Central Africa, Tervuren, Belgium; Natural History Museum, London, United Kingdom; Royal Belgian Institute of Natural Sciences, Brussels, Belgium; Natural History Museum of Denmark, Copenhagen, Denmark; Naturalis Biodiversity Center, Leiden, the Netherlands. 


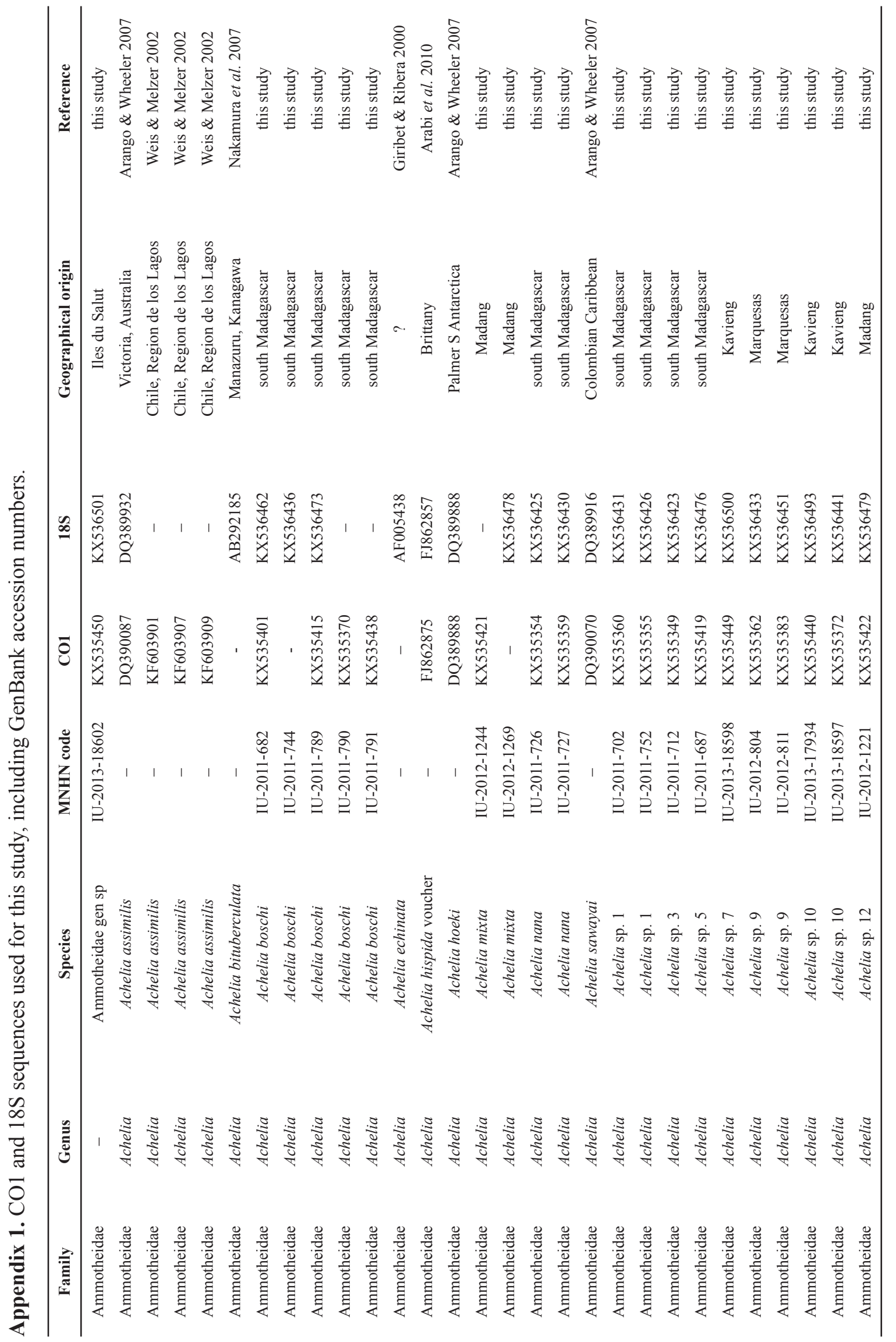




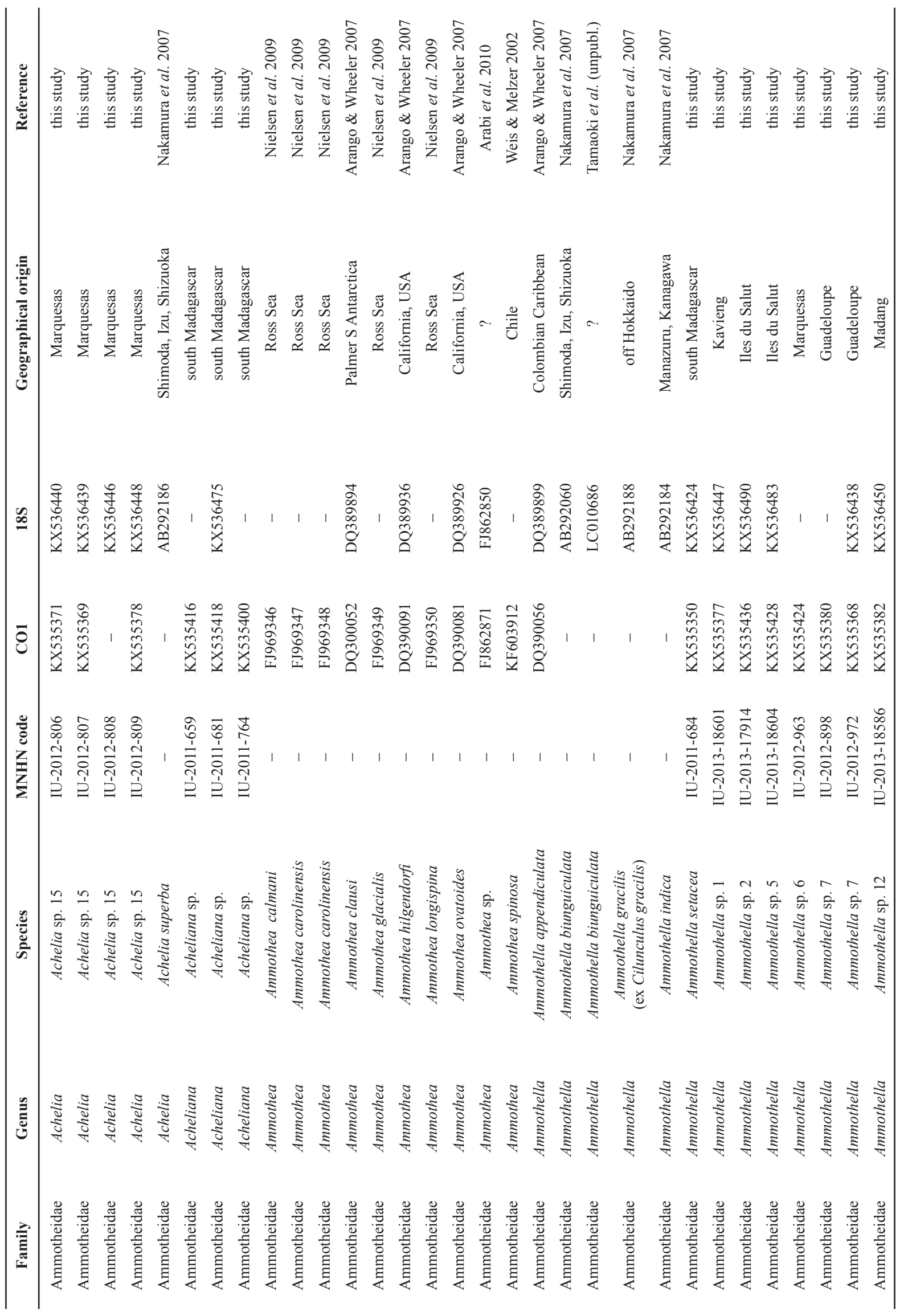




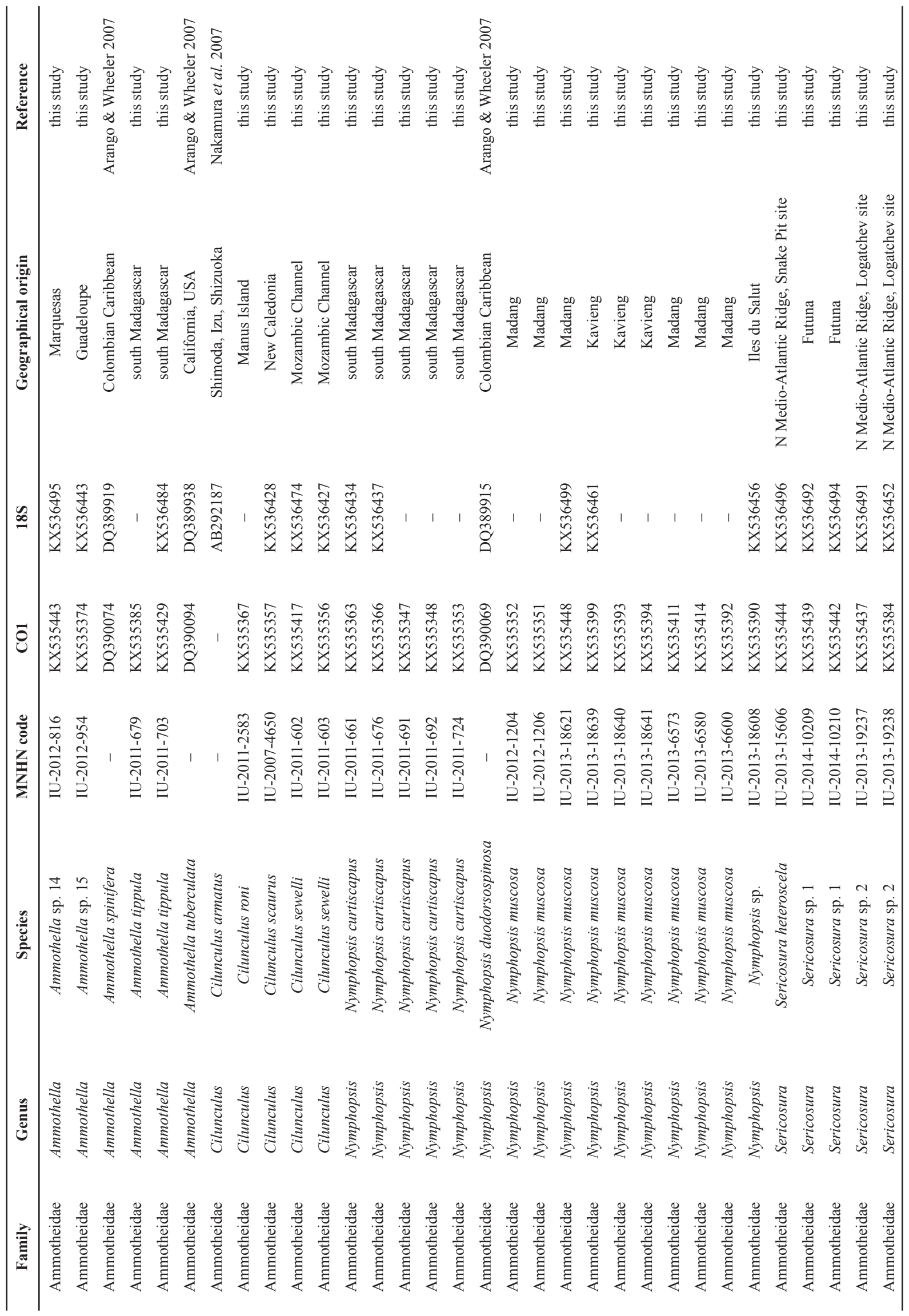




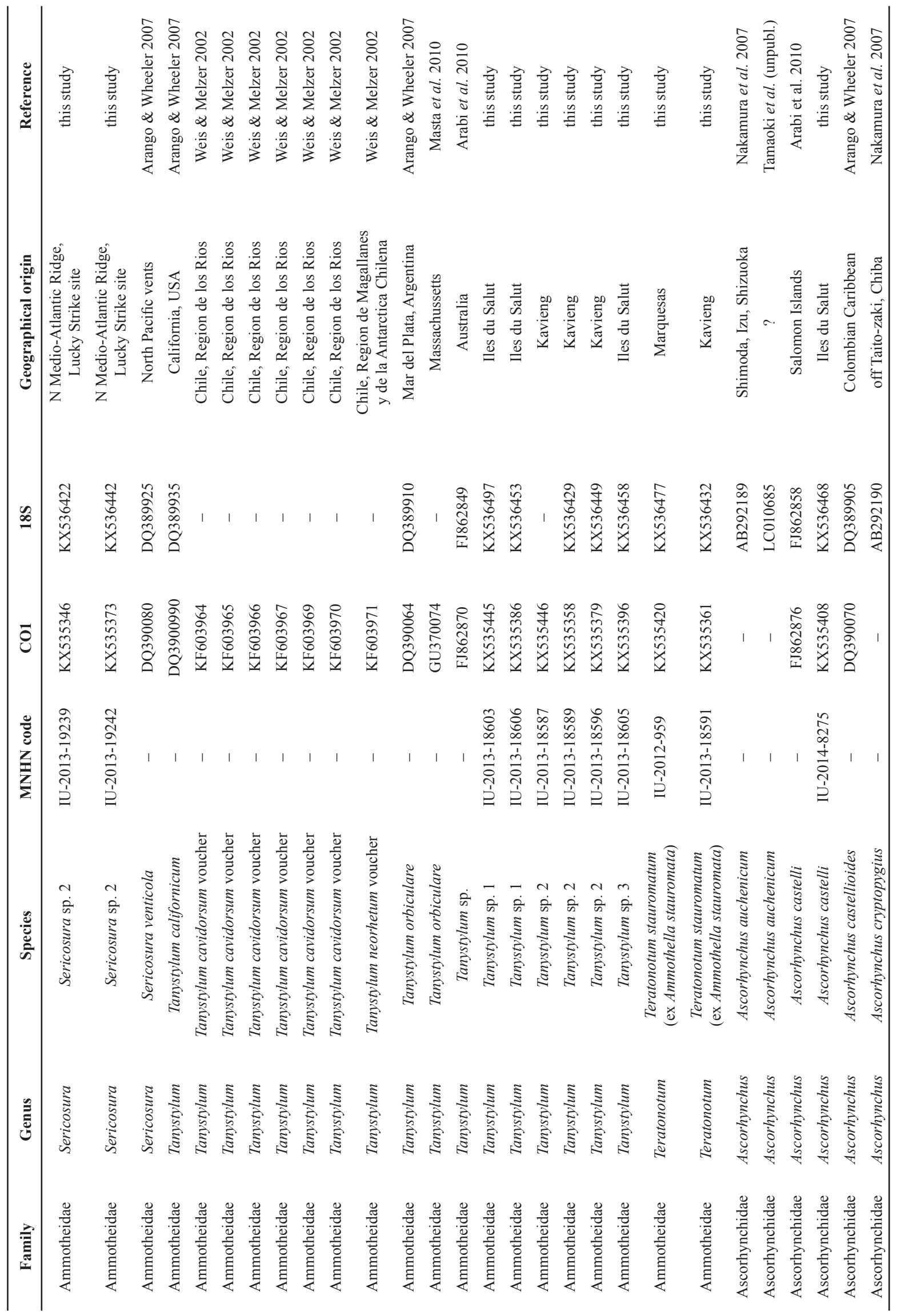




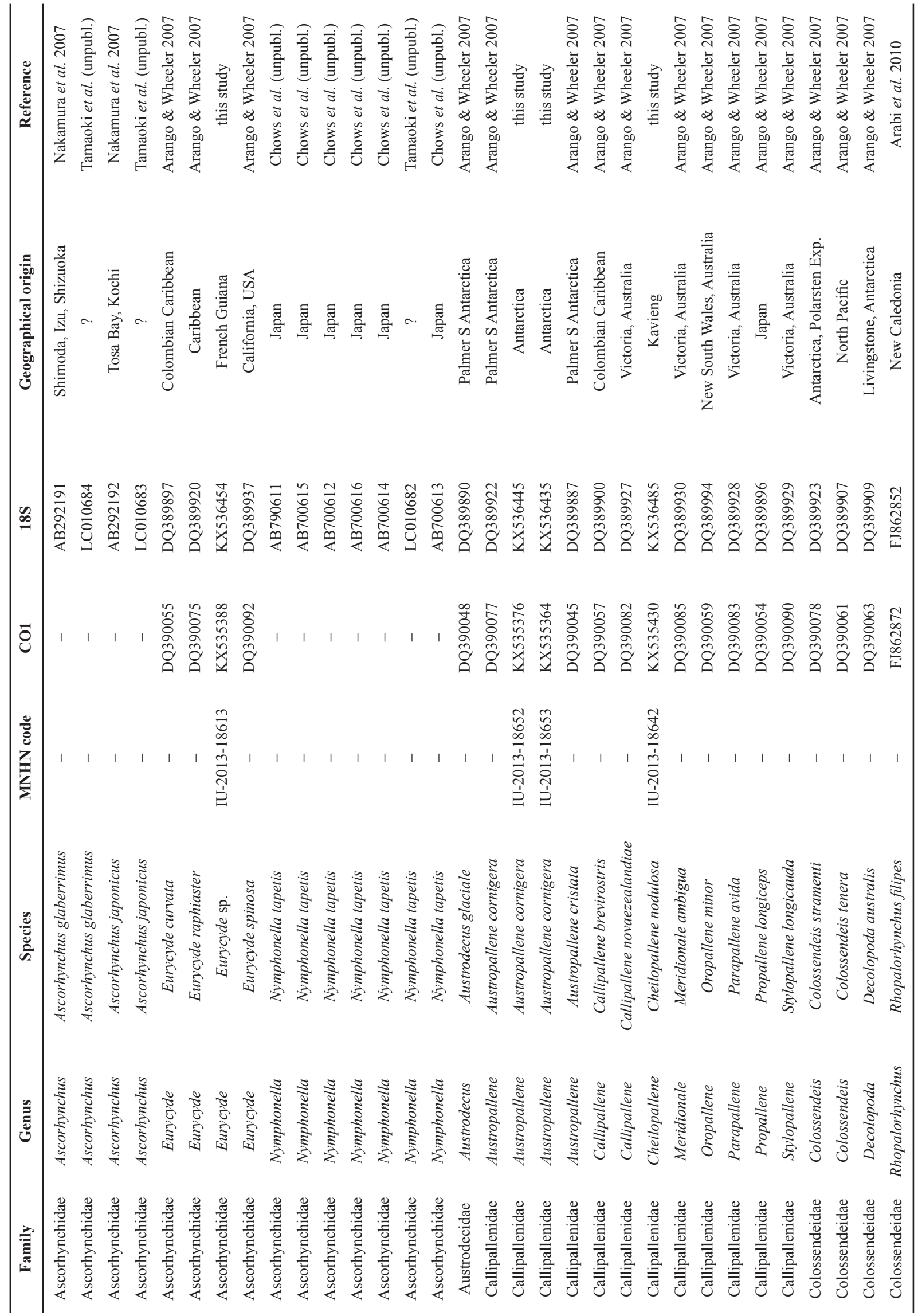




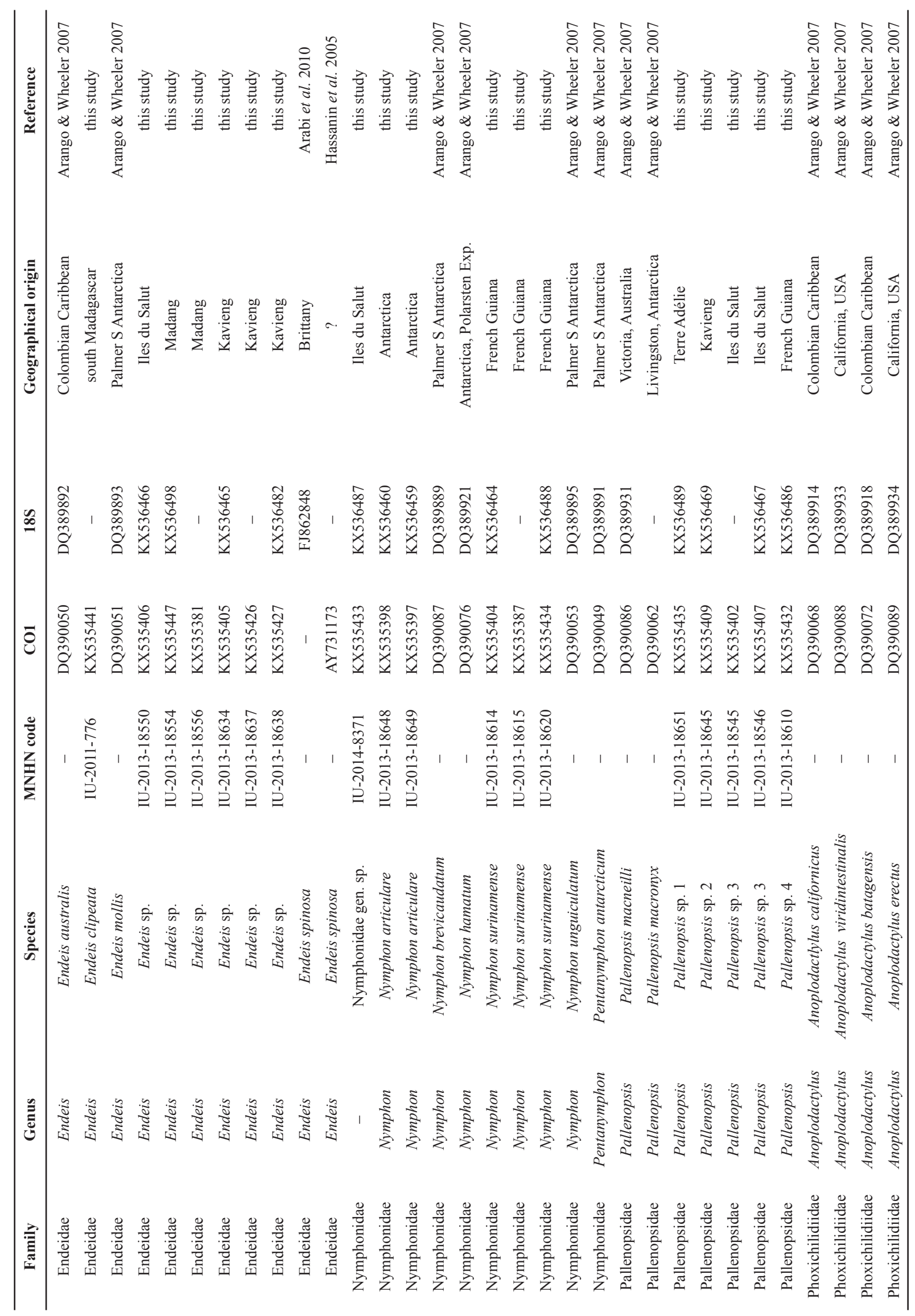




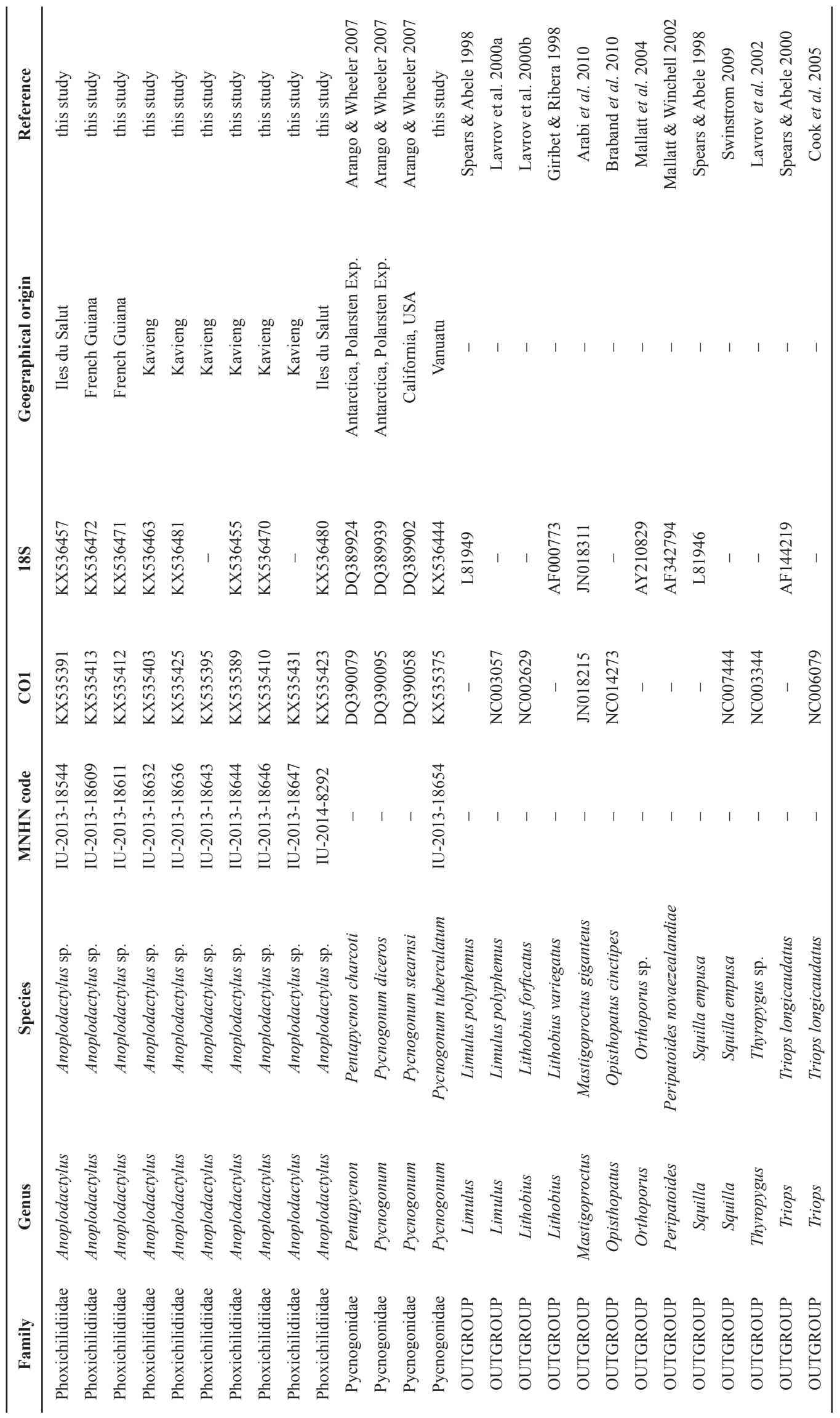




\section{References for Appendix 1:}

Arabi J., Cruaud C., Couloux A. \& Hassanin A. 2010. Studying sources of incongruence in arthropod molecular phylogenies: sea spiders (Pycnogonida) as a case study. Comptes Rendus Biologies 333 (5): 438-453. http://dx.doi.org/10.1016/j.crvi.2010.01.018

Arango C.P. \& Wheeler W.C. 2007. Phylogeny of the sea spiders (Arthropoda, Pycnogonida) based on direct optimization of six loci and morphology. Cladistics 23 (3): 255-293. http://dx.doi.org/10.1111/ j.1096-0031.2007.00143.x

Braband A., Cameron S.L., Podsiadlowski L., Daniels S.R. \& Mayer G. 2010. The mitochondrial genome of the onychophoran Opisthopatus cinctipes (Peripatopsidae) reflects the ancestral mitochondrial gene arrangement of Panarthropoda and Ecdysozoa. Molecular Phylogenetics and Evolution 57 (1): 285-292. http://dx.doi.org/10.1016/j.ympev.2010.05.011

Cook C.E., Yue Q. \& Akam M. 2005. Mitochondrial genomes suggest that hexapods and crustaceans are mutually paraphyletic. Proceedings of the Royal Society of London B 272 (1569): 1295-1304. http:// dx.doi.org/10.1098/rspb.2004.3042

Giribet G. \& Ribera C. 1998. The position of arthropods in the animal kingdom: a search for a reliable outgroup for internal arthropod phylogeny. Molecular Phylogenetics and Evolution 9 (3): 481-488. http://dx.doi.org/10.1006/mpev.1998.0494

Giribet G. \& Ribera C. 2000. A review of arthropod phylogeny: new data based on ribosomal DNA sequences and direct character optimization. Cladistics 16 (2): 204-231. http://dx.doi. org/10.1111/j.1096-0031.2000.tb00353.x

Hassanin A., Léger N. \& Deutsch J. 2005. Evidence for multiple reversals of asymmetric mutational constraints during the evolution of the mitochondrial genome of Metazoa, and consequences for phylogenetic inferences. Systematic Biology 54 (2): 277-298.

Lavrov D.V., Boore J.L. \& Brown W.M. 2000a. The complete mitochondrial DNA sequence of the horseshoe crab Limulus polyphemus. Molecular Biology and Evolution 17 (5): 813-824. http://dx.doi. org/10.1093/oxfordjournals.molbev.a026360

Lavrov D.V., Brown W.M. \& Boore J.L. 2000b. A novel type of RNA editing occurs in the mitochondrial tRNAs of the centipede Lithobius forficatus. Proceedings of the National Academy of Sciences 97 (25): 13738-13742. http://dx.doi.org/10.1073/pnas.250402997

Lavrov D.V., Boore J.L. \& Brown W.M. 2002. Complete mtDNA sequences of two millipedes suggest a new model for mitochondrial gene rearrangements: duplication and nonrandom loss. Molecular Biology and Evolution 19 (2): 163-169. http://dx.doi.org/10.1093/oxfordjournals.molbev.a004068

Mallatt J. \& Winchell C.J. 2002. Testing the new animal phylogeny: first use of combined large-subunit and small-subunit rRNA gene sequences to classify the protostomes. Molecular Biology and Evolution 19 (3): 289-301. http://dx.doi.org/10.1093/oxfordjournals.molbev.a004082

Mallatt J. M., Garey J.R. \& Shultz J.W. 2004. Ecdysozoan phylogeny and Bayesian inference: first use of nearly complete $28 \mathrm{~S}$ and $18 \mathrm{~S}$ rRNA gene sequences to classify the arthropods and their kin. Molecular Phylogenetics and Evolution 31 (1): 178-191. http://dx.doi.org/10.1016/j.ympev.2003.07.013

Masta S.E., McCallA. \& Longhorn S.J. 2010. Rare genomic changes and mitochondrial sequences provide independent support for congruent relationships among the sea spiders (Arthropoda, Pycnogonida). Molecular Phylogenetics and Evolution 57 (1): 59-70. http://dx.doi.org/10.1016/j.ympev.2010.06.020

Nakamura K., Kano Y., Suzuki N., Namatame T. \& Kosaku A. 2007. 18S rRNA phylogeny of sea spiders with emphasis on the position of Rhynchothoracidae. Marine Biology 153 (2): 213-223. http:// dx.doi.org/10.1007/s00227-007-0803-0 
Nielsen J.F., Lavery S. \& Lörz A.N. 2009. Synopsis of a new collection of sea spiders (Arthropoda: Pycnogonida) from the Ross Sea, Antarctica. Polar Biology 32 (8): 1147-1155. http://dx.doi.org/10.1007/ $\underline{\mathrm{s} 00300-009-0611-8}$

Spears T. \& Abele L.G. 1998. Crustacean phylogeny inferred from 18S rDNA. In: Fortey R.A. \& Thomas R.H. (eds) Arthropod Relationships: 169-187. Springer Netherlands, Dordrecht. http://dx.doi. org/10.1007/978-94-011-4904-4_14

Spears T. \& Abele L.G. 2000. Branchiopod monophyly and interordinal phylogeny inferred from $18 \mathrm{~S}$ ribosomal DNA. Journal of Crustacean Biology 20 (1): 1-24. http://dx.doi.org/10.1163/20021975$\underline{99990012}$

Swinstrom K. 2009. The first complete mitochondrial genome sequences for stomatopod crustaceans: implications for phylogeny. Lawrence Berkeley National Laboratory. Available from http://escholarship. org/uc/item/4s4023bb [accessed 1 February 2017].

Weis A. \& Melzer R.R. 2012. How did sea spiders recolonize the Chilean fjords after glaciation? DNA barcoding of Pycnogonida, with remarks on phylogeography of Achelia assimilis (Haswell, 1885). Systematics and Biodiversity 10 (3): 361-374. http://dx.doi.org/10.1080/14772000.2012.716462 
Appendix 2A. Bayesian tree of Pycnogonida based on $135 \mathrm{CO} 1$ sequences (un-partitioned analysis). Coloured rectangles show non-ammotheid families, and coloured branches discriminate ammotheid genera. The numbers at the nodes indicate the posterior probabilities superior to 0.5 . Asterisks associated to taxon names indicate holotype specimens. Outgroups were removed for better readability.

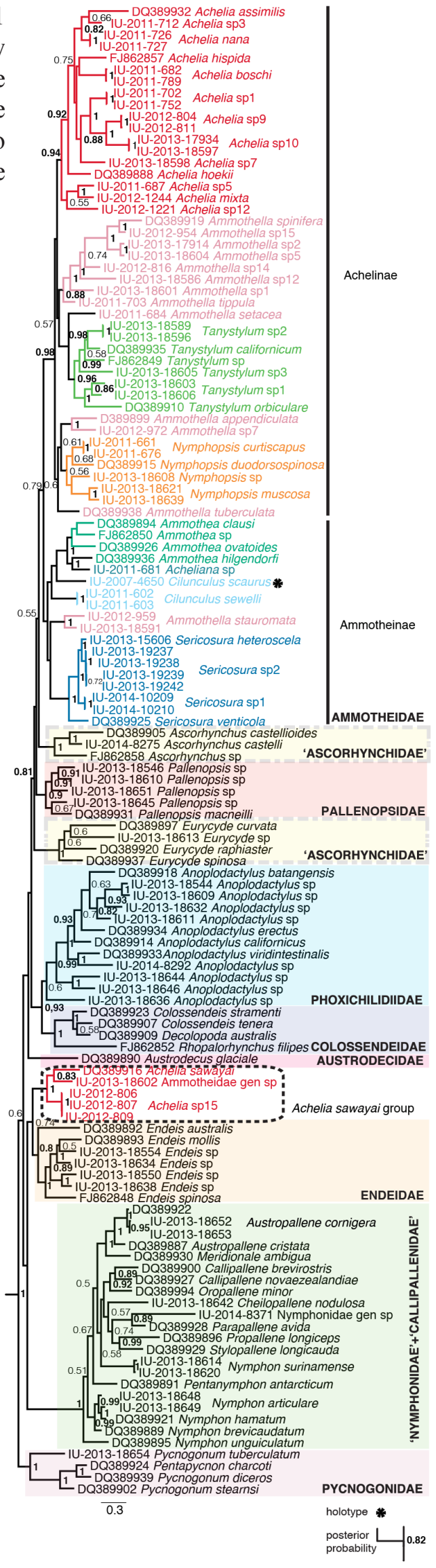


Appendix 2B. Bayesian tree of Pycnogonida based on $13518 \mathrm{~S}$ sequences. Coloured rectangles show non-ammotheid families, and coloured branches discriminate ammotheid genera. The numbers at the nodes indicate the posterior probabilities superior to 0.5 . Asterisks associated to taxon names indicate holotype specimens. Outgroups were removed for better readability.

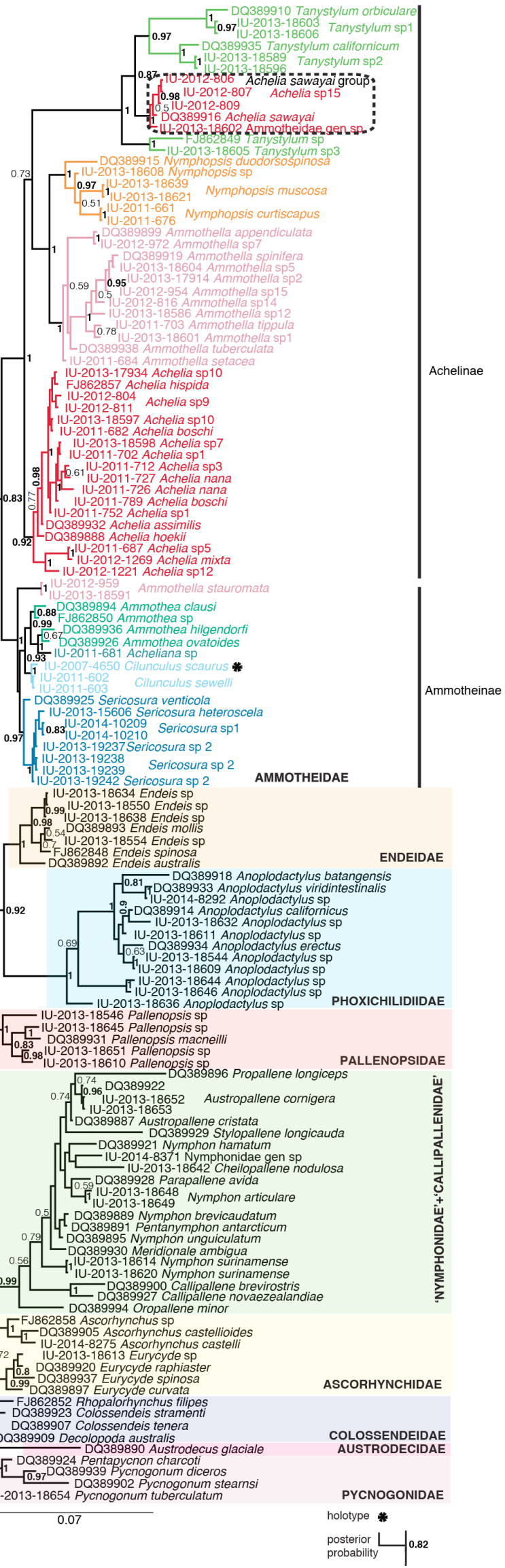

